\title{
Three Essays on Job Loss Fears and Offshoring
}

\author{
Dissertation
}

zur Erlangung des wirtschaftswissenschaftlichen Doktorgrades der Wirtschaftswissenschaftlichen Fakultät der Universität Göttingen

vorgelegt von

Maximilian Riedl

aus Neuburg an der Donau

Göttingen, 2014 
Erstbetreuer:

Zweitbetreuer:
Prof. Ingo Geishecker, PhD

Juniorprofessor Dr. Thushyanthan Baskaran

Tag der mündlichen Prüfung: 28. November 2013 


\section{Danksagung}

Mein größter Dank gilt Prof. Ingo Geishecker, $\mathrm{PhD}$, für die exzellente Betreuung, für seine Geduld, Inspiration und Rückendeckung, sodass ich meine Forschungsarbeit frei gestalten konnte.

Außerdem möchte ich mich herzlich bei meinem Zweitbetreuer Dr. Thushyanthan Baskaran für die Unterstützung und die konstruktive Kritik bedanken. Für seine Mitgliedschaft in der Prüfungskommission bedanke ich mich bei Herrn Prof. Dr. Michael Wolff.

Als Hilfskräfte waren mir Wadim Djatschenko, Carola Müller, Christian Kliche und Martin Breßlein eine große Unterstützung. Besonders möchte ich mich bei Martin Breßlein für seine Programmierleistung bedanken.

Meinen Freunden und Kollegen der Lehrstühle von Prof. Dr. Renate Ohr und Prof. Dr. Kilian Bizer möchte ich für die vielen konstruktiven und inspirierenden Gespräche während meiner gesamten Zeit an der Georg-August-Universität Göttingen danken. Spezieller Dank gebührt Jörg König, Nora Vogt und Tim Ehlers.

Diese Arbeit entstand im Rahmen des von der Deutschen Forschungsgemeinschaft finanzierten Drittmittelprojekts "International outsourcing, job loss fears and wage bargaining" (Ge 2074/1-2). Für die finanzielle Unterstützung bedanke ich mich herzlich.

Ohne die Unterstützung und das Vertrauen meiner Eltern und Geschwister wäre meine Dissertation nicht entstanden. Ihnen widme ich diese Arbeit. 


\section{Contents}

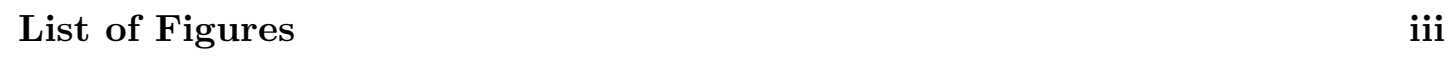

List of Tables

$\begin{array}{lr}\text { Introduction } & 1\end{array}$

1 Keep it simple: estimation strategies for ordered response models

$\begin{array}{ll}\text { with fixed effects } & 9\end{array}$

1.1 Introduction . . . . . . . . . . . . . . . . . . . . . . . . . . . 9

1.2 Estimation Strategies in Detail . . . . . . . . . . . . . . . . . 11

1.3 Monte Carlo simulation and results . . . . . . . . . . . . . . . . . 16

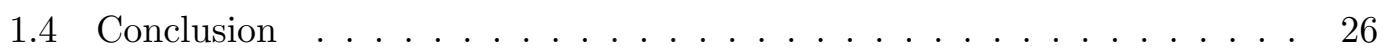

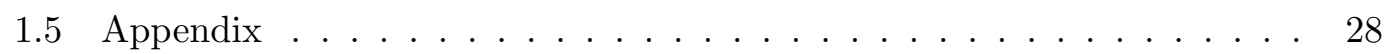

2 Offshoring and Job Loss Fears: An Econometric Analysis of Individual

$\begin{array}{ll}\text { Perceptions } & 29\end{array}$

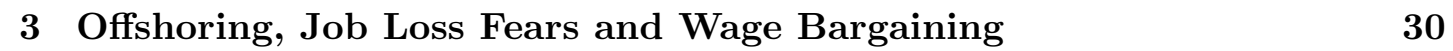

3.1 Introduction . . . . . . . . . . . . . . . . . . . . . . . . 30

3.2 Literature . . . . . . . . . . . . . . . . . . . . . . . . . . . . . . . 32

$3.3 \quad$ Wage bargaining with job loss fears . . . . . . . . . . . . . . . . . 34

3.3 .1 Firms $\ldots \ldots \ldots \ldots \ldots \ldots$

3.3 .2 Labour market . . . . . . . . . . . . . . . . . . . . . 36

$3.3 .3 \quad$ Nash wage bargaining $\ldots \ldots \ldots \ldots$. . . . . . . . . . . . 39

$3.3 .4 \quad$ Stage 2

$3.3 .5 \quad$ Stage $1 \ldots \ldots \ldots \ldots$. . . . . . . . . . . . . . 40

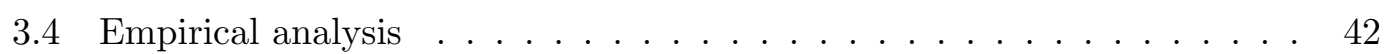

$3.4 .1 \quad$ Data . . . . . . . . . . . . . . . . . . . . . . . 43

$3.4 .2 \quad$ Empirical model and identification . . . . . . . . . . . . . . 44

3.4 .3 Estimation results . . . . . . . . . . . . . . . . . . 47

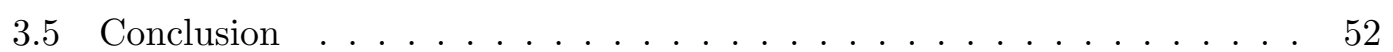

\begin{tabular}{ll}
\hline References & 53
\end{tabular} 


\section{List of Figures}

$3.1 \quad$ Utility function for different k. $A$ : maximum utility for $k=2 . \ldots 38$ 


\section{List of Tables}

$1.1 \quad$ Monte Carlo simulation results for $K=3, T=5 \ldots \ldots \ldots \ldots \ldots$

$1.2 \quad$ Monte Carlo simulation results for $K=3, I=1000 \ldots \ldots \ldots$

1.3 Monte Carlo simulation results for $K=3, I=3000, T=6 \ldots$. . . . . 21

1.4 Monte Carlo simulation results for different distributions of the explana-

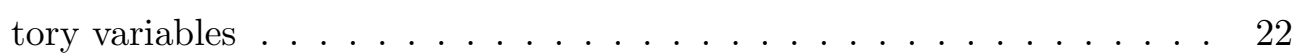

$1.5 \quad$ Monte Carlo simulation results for $I=3000, T=12 \ldots \ldots \ldots \ldots$

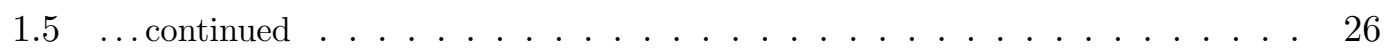

3.1 Descriptive statistics $\ldots \ldots \ldots \ldots \ldots \ldots$. . . . . . . . . . . . . . . . . . . . . . . 46

$3.2 \quad$ Fixed effects OLS wage regressions . . . . . . . . . . . . . . . . . . . . 48

3.3 Marginal effects of potential offshoring by fear level . . . . . . . . . . . . 50

3.4 Average yearly wage effect of potential offshoring by fear level . . . . . . 51 


\section{Introduction}

Globalisation and the steadily growing international trade have caused major changes in labour markets. Falling trade barriers and trade costs, as well as innovations in the field of information and communications technology make it easier for firms to shift parts of their production abroad or to purchase intermediate inputs at arm's length on international markets, thereby replacing domestic jobs. Apart from the gains from trade and specialisation, many employees also realise that due to the increasing international fragmentation of production processes their own jobs are at risk. Hence, when asking people about their attitudes towards globalisation, often the public viewpoint does not coincide with the commonly-received opinion of trade economists.

Economic research on employment and wage effects of offshoring or international outsourcing already encompasses a large body of literature. It identifies winners and losers resulting from increasing offshoring, e.g., growing wage dispersion between highand low-skilled workers. However, the vast majority of literature focuses on objective labour market effects and neglects subjective effects of offshoring, such as the fear of job loss. This thesis addresses the effect of offshoring on job loss fears as well as their role during wage negotiations in more detail.

In the following, the terms offshoring or international outsourcing describe the same phenomenon, namely sourcing of intermediate inputs from a foreign country, either from a foreign affiliate or purchased at arm's length (see, e.g. Helpman, 2006). As opposed to foreign direct investments (FDI), offshoring can also take place without FDI, such as arm's length transactions. Moreover, the motivation for FDI is mostly of horizontal nature and consequently disaccording with the definition of offshoring.

Offshoring takes place in both manufacturing and service industries. Although service offshoring is an increasing phenomenon, this thesis looks at the effects of offshoring in manufacturing only, since offshoring in manufacturing played and still plays the major role in total offshoring activities. Furthermore, trade data coverage for service industries is still limited and thus difficult to use for empirical analysis over a longer period of time. 
The increasing possibility for firms to shift parts of their production abroad and simultaneously shut down domestic plants has been recognized as a threat by the public opinion. When individuals lose their jobs and become unemployed, they do not only lose their income but also face additional negative effects. Nickell, Jones and Quintini (2002) show that workers also suffer from negative wage declines after re-employment even in the long run. Furthermore, Winkelmann and Winkelmann (1998) highlight the negative effect of unemployment on individual life satisfaction, which is more severe than the loss of income. The effect on life satisfaction has been identified as three times bigger than being in bad health. Additionally, the negative impact of unemployment on life satisfaction does not disappear over time and goes together with a social loss which decreases life satisfaction even more. Even for workers who stay employed, Di Tella, MacCulloch and Oswald (2001) find that rising unemployment has a negative impact on their well-being. For these reasons, it is not surprising that job security is one of the most important aspects of subjective perceptions on job satisfaction, as well as individual well-being or life satisfaction.

Moreover, the fear of job loss also has significant implications for other areas in economics like, e.g., wages or consumption behaviour. In Blanchflower (1991), the author finds negative effects of increasing perceived job insecurity on wages for workers in the UK. Further, Stephens, Jr. (2004) and Benito (2006) show that individual perceptions of job insecurity can play an important role for individual household consumption, and are valid predictors for actual future job loss. Lastly, according to Frey and Stutzer (2002) or Layard (2011) individual perceptions concerning job security and the fear of job loss are important also from a welfare perspective, as it is a major determinant of individual well-being and happiness.

Interestingly, the impact of offshoring on individually perceived job loss fears has not yet been investigated in the economic literature. Only Scheve and Slaughter (2004) uses British household panel data together with industry data on FDI and find that increasing FDI activities raises perceived job insecurity. As mentioned above, FDI and offshoring differ not only in motivation and accordingly should not be treated equally. Thus this thesis tries to fill the gap in the existing literature by assessing the impact of offshoring on individual job loss fears. 
The existing theoretical literature regarding the labour market effects of offshoring is already very profound, but at the same time it cannot show unambiguous evidence for the specific direction of the effects.1 Depending on the model assumptions, e.g., Feenstra and Hanson (1996a), Arndt $(1997,1999)$ or Kohler (2004) can identify negative or positive effects on relative wages for low- and high-skilled workers in a general equilibrium framework with competitive labour markets.

Theoretical studies with imperfect labour markets also point to contrary effects on wages and employment caused by offshoring. In these models wages are negotiated between firms and trade unions. Wages can exceed the competitive level so that there is the possibility of unemployment. The contrary wage effect results from the important distinction between actual offshoring and the threat of potential but not realised offshoring. For example, Skaksen (2004) and Ranjan (2013) argue that firms can use the threat of potential offshoring during negotiations in order to lower wages, while actual or realised offshoring can rise wages for remaining workers due to productivity gains or decreasing elasticity of labour demand. However, what is still missing in the literature is the concrete channel through which the threat of potential offshoring impacts on wages.

In the existing empirical literature, the distinction between actual and potential offshoring has not been addressed so far. Instead, empirical studies find negative and positive effects of actual offshoring on wages or employment through differentiating for different skills or tasks. In these studies, individual micro level data on wages and other personal characteristics are matched together with aggregate data on offshoring intensities at the industry level. However, this data is only quantifying actual or realised offshoring and thus can only reflect parts of the threat of potential offshoring. Still, those studies show empirical evidence for negative wage effects of offshoring for lowskilled workers and positive effects for high-skilled (see, e.g., Geishecker and Görg, 2008 or Hummels et al., 2010). Furthermore, Baumgarten, Geishecker and Görg (2013) show for Germany that offshoring reduces the wage of workers who perform routine and non-interactive tasks, irrespective of their skill level.

\footnotetext{
${ }^{1}$ For an extensive review of the existing literature of wage and employment effects of offshoring see, e.g., Crinò (2009) or Harrison, McLaren and McMillan (2011).
} 
Although there is large empirical evidence on wage effects caused by increasing actual offshoring, the literature still lacks of a detailed analysis of the threat of potential offshoring on wages. Thus, this thesis tries to contribute to the existing literature with an assessment of the role of job loss fears in wage bargaining and to improve economic understanding on how the threat of potential offshoring impacts on wages.

In most surveys where people are asked about their own happiness or subjective well-being, respondents have to rate their feelings on an ordered scale. In this thesis the reported level on job loss fears is measured on a three-point scale. Working with data on individual happiness, Ferrer-i-Carbonell and Frijters (2004) show that controlling for time fixed unobserved individual heterogeneity is crucial to get unbiased parameter

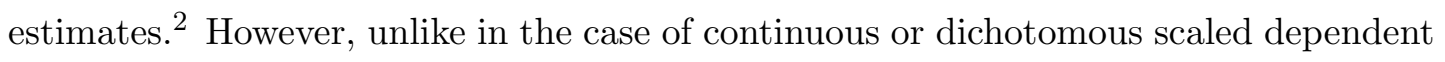
variables, a consistent estimator for ordinal response data, which also accounts for unobserved personality traits, does not exist.

In Ferrer-i-Carbonell and Frijters (2004), a new approach of a conditional ordered logit estimator has been introduced that allows controlling for unobserved individual heterogeneity. Besides several other existing estimation strategies pursued in the empirical literature, this estimator was promising in two ways. First, it should capture more of the ordinal variation in the data by using individual specific thresholds for the binary recoding of the ordered response variable. Second, it should deliver parameter estimates with the lowest variance because it chooses the individual threshold that minimizes the Hessian function used to derive the variance covariance matrix for the estimates. For these two reasons, several studies already applied this estimator analysing ordered response data on individual happines 4 . However, there is missing knowledge on the asymptotic and finite sample properties of this estimator. Furthermore, since there are several other estimation strategies dealing with ordered response data and individual unobserved heterogeneity, there is still no evidence on how they compare to each other in terms of consistency and efficiency.

\footnotetext{
${ }^{2}$ De Neve, Christakis, Fowler and Frey (2012) recently found that $33 \%$ of variation in individual happiness is based on genetic predisposition. Not controlling for those fixed individual characteristics can certainly result in biased estimation results.

${ }^{3}$ Empirical studies using this estimation method are, e.g., Frijters, Geishecker, Haisken-De-New and Shields (2006), Frijters, Haisken-DeNew and Shields (2004), Knabe and Rätzel (2009), Clark, Knabe and Rätzel (2010) and Geishecker, Riedl and Frijters (2012).
} 
Therefore, the first chapter of this thesis compares different estimation strategies of ordered response models in the presence of non-random unobserved heterogeneity. This is done by running Monte Carlo simulations on randomly generated artificial data with predetermined parameters. All simulations are performed 1000 times for different sample sizes, ordinal scales, number and distribution of covariates. The considered estimation strategies include, inter alia, the estimator of Ferrer-i-Carbonell and Frijters (2004) (FCF), the recently developed blow up and cluster (BUC) conditional logit estimator of Baetschmann, Staub and Winkelmann (2011) the simple binary conditional logit, the linear fixed effect estimator and other methods used in the literature.

The main contribution of this chapter is an evaluation of finite sample properties of the recently developed conditional logit estimators for ordered response data and their comparison with regard to consistency and efficiency. For this purpose, the conditional logit estimator, as proposed by Ferrer-i-Carbonell and Frijters (2004), was programmed in STATA and is now available as a free download 5 Additionally, this chapter also provides a practical guideline for applied research on ordered response data.

One of its main findings is that the FCF method cannot meet the expectations, however the BUC estimation method delivers unbiased and efficient estimates. Furthermore, the simple linear fixed effects model can be recommended if the relative sizes of the parameters are of interest. The linear fixed effects model provides correct coefficient ratios and thus leads to the same results as from the non-linear estimators. This finding has already been recognized by Greene (1981), Chung and Goldberger (1984) or Deaton and Irish (1984) about 30 years ago. Nevertheless, highlighting this finding again is one of the major contributions of chapter 1 , since it seems to be forgotten in today's empirical literature on happiness economics.

In the second chapter the estimation methods of Ferrer-i-Carbonell and Frijters (2004) and Baetschmann et al. (2011), evaluated in the first chapter, are applied to quantify the impact of offshoring and other globalisation measures on individual perceptions of job loss fears. This analysis combines industry-level offshoring measures

\footnotetext{
${ }^{4}$ Among the studies using this estimator are, e.g., Frijters and Beatton (2012), Cho and Vadlamannati (2012) and Bell, Otterbach and Sousa-Poza (2011).

${ }^{5}$ The STATA ado-file of the command called $f c f$ is published online and public available at http://hdl.handle.net/11022/0000-0000-1F7A-6.
} 
with micro-level data from the SOEP, a representative longitudinal survey of private households in Germany. The unbalanced sample consists of male and female full or part time employed workers in manufacturing industries for the years 1995 to 2006. Industry offshoring data are derived from the Eurostat COMEXT data base and inputoutput tables from the German Federal Statistical Office using the extended framework of Feenstra and Hanson (1996a, 1996b, 1999). Additionally, the empirical model controls for industry-level foreign direct investment (FDI) and import penetration plus migration at the federal state level. individually perceived job loss fears is measured on a three-stage scale ranging from not concerned over somewhat concerned to very concerned. The empirical model also controls for individual unobserved characteristics, industry and time fixed effects. Thus, only changes of the industry specific offshoring intensity within the individual identifies the offshoring effect on job loss fears. To consider the impact of offshoring in more detail, three different specifications are estimated. Firstly, the impact of aggregated offshoring is estimated, then offshoring is disaggregated towards low-wage and high-wage countries, and finally disaggregated offshoring is interacted with skill level in order to get a differentiated effect of offshoring by each worker's the level of education.

In that way, this chapter is the first paper that estimate the impact of international offshoring on individually perceived job security. Interestingly, its findings are to some extent contrary to what one would expect according to theoretical and empirical considerations on actual job loss risks.

The results indicate that offshoring to low-wage countries significantly raises job loss fears whilst offshoring to high-wage countries lowers them. This result may be explained with different offshoring motives of firms. When companies operate offshoring to lowwage countries in order to save costs and to substitute domestic labour, this may have a negative impact on job loss fears. Whereas offshoring to high-wage countries can also be motivated by other reasons, such as entering new markets, and as a result lead to more secure domestic workplaces. Over the sample period from 1995 to 2006, offshoring to low and high-wage countries together can account for about 13 percent of the total increase in job loss fears.

Another interesting result is that the negative effect of offshoring is most pronounced 
for high-skilled, although their objective job loss risk is lower relative to low-skilled workers. The reason might be that high-skilled workers would suffer from higher income cuts in the event of unemployment. Additionally, high-skilled workers may have to accept greater wage losses than low-skilled workers when they get re-employed.

In their recently published article Böckerman and Maliranta (2013) confirm the negative implications of offshoring towards low-wage countries on employer well-being with linked employer-employee data from Finland. They also reveal a "silver lining" for workers who stay employed. Increasing offshoring towards high-wage countries enhances intra-firm reallocations of occupations which improves workers' well-being due to better prospects of promotion.

The third chapter assesses the impact of job loss fears and potential offshoring on wages, both theoretically and empirically. The theoretical model assumes imperfect labour markets, in which firms and workers collectively negotiate over wages. Bargaining takes place in a right-to-manage setting, in which firms set the amount of labour demand after wage negotiations. Firms produce one good with two input factors and can chose either to produce in-house or to purchase one of the two inputs as intermediate good from abroad, i.e. to operate offshoring. All workers are organized in one trade union and have a disutility from perceiving subjective job loss fears. These fears are modelled as the product of the perceived probability of job loss times the subjective costs of job loss. During wage negotiations firms can use the possibility to offshore as a threat to increase workers' job loss fears. The Nash solution of the wage bargaining model shows that increasing job loss fears, induced by the threat of potential offshoring, lowers the wage of domestic workers.

The main contribution of this chapter is the explicit description of individual job loss fears in the union members' utility function within a wage bargaining setting. The parameter that describes the individual subjective fear of job loss in now part of the Nash bargaining solution. Hence, it is now possible to show the negative impact of job loss fears on wages through the threat of potential offshoring.

In the empirical analysis individual data on wages, perceived job loss fears and other demographic characteristics from the German Socio Economics Panel (SOEP) 
are combined with industry level data on actual and potential offshoring. Since there is no actual measure for potential offshoring, it is approximated by world wide export supply of intermediate goods. The empirical results match with the theoretical findings, that is, increasing job loss fears lower wages. Workers who switch to the highest fear category earn about 1.6 percent less per hour than workers in lower fear categories. Instead of actual offshoring it is potential offshoring to low-wage countries which lowers wages. Further, it can be shown that increasing potential offshoring to low-wage countries lowers wages differently through the level of individually perceived fear of job loss.

This thesis shows the importance of individually perceived job loss fears in a globalised world. One important finding is that offshoring has a significant effect on these fears. Furthermore, it is shown that offshoring impacts on wages through job loss fears. In particular, it is the threat of potential offshoring and not actual offshoring that lowers wages. Thus, the distinction between potential and actual offshoring and its effects on labour markets should be at the forefront of future research in this field.

Due to the negative effects of offshoring on job loss fears and the resulting wage cuts, one may invoke policy to intervene. However, policy should neither restrict offshoring nor interfere in free collective bargaining between employers and trade unions. Instead, it should be the aim of public policy to lower the fears of job loss and improve happiness, just like Layard $(2006,2011)$ proposes. Possible solutions might include generous social security benefits, useful further education for employees or flexible labour markets for fast re-employment. 


\section{Keep it simple: estimation strategies for or- dered response models with fixed effects 1}

Authors: Maximilian Riedl and Ingo Geishecker

\section{$1.1 \quad$ Introduction}

When estimating models for longitudinal ordinal response data, researchers typically face the problem of accounting for unobserved personality traits that may be correlated with explanatory variables, while at the same time accommodating the ordinal nature of the dependent variable. Since there is no consistent estimator for an ordered logit or probit model that can explicitly incorporate individual fixed effects, different estimation strategies have been pursued in the literature. Yet, the literature provides no guideline for when to use which estimator.

Authors such as Winkelmann and Winkelmann (1998), Senik (2004), Clark (2003) and Kassenböhmer and Haisken-DeNew (2009) recode the ordinal dependent variable into a binary variable and subsequently apply the conditional logit estimator of Chamberlain (1980). This approach has the advantage that it maintains the nonlinear character of the dependent variable. However, recoding ordinal responses into binary responses requires the researcher to more or less arbitrarily define a threshold above which the dependent binary variable takes the value one. As a consequence, potentially important variation in the original ordinal response variable is disregarded.

Extending this approach, Ferrer-i-Carbonell and Frijters (2004) propose an estimation strategy that uses much more of the variation in the ordinal response variable for binary recoding. However, since this procedure requires calculation of the individual Hessian for each binary recoding option, it is computationally very expensive. Nevertheless, the estimator has gained some popularity and has been employed in a number of recent empirical studies, such as Frijters et al. (2006), Frijters et al. (2004), Knabe

\footnotetext{
${ }^{1}$ This chapter was published in an earlier version as: "Ordered Response Models and Non-Random Personality Traits: Monte Carlo Simulations and a Practical Guide", CEGE Discussion Papers No. $116,2012$.
} 
and Rätzel (2009), Clark et al. (2010) and Geishecker et al. (2012).

Another binary recoding strategy is developed in Baetschmann et al. (2011). Their so called "Blow-Up and Cluster" (BUC) estimator aims at using all variation of the ordinal response variable by expanding the data set to accommodate all possible binary recoding options of the ordered dependent variable. The approach has been used in, e.g., Geishecker et al. (2012).

A fourth and very common approach taken, for example, by Di Tella et al. (2001), Scheve and Slaughter (2004), and Senik (2004), assumes cardinality of the ordered response variable and estimates a simple first difference or within-transformed linear model. Although certain applications, such as studies of subjective well-being, have shown that the cardinality assumption does not severely bias estimates (see Ferrer-iCarbonell and Frijters, 2004), it is difficult to generalize this finding to other applications. To circumvent violations of the cardinality assumption van Praag and Ferreri-Carbonell (2008) propose to rescale the ordered dependent variable to a normal distributed variable centered around zero. The so called "probit-adapted OLS" technique has been used by, e.g., Stevenson and Wolfers (2008), Luechinger (2009), Clark et al. (2010), Luechinger, Meier and Stutzer (2010), and Geishecker (2012).

Choosing from this arsenal of estimation strategies is not an easy task, since apart from rough comparisons of the alternatives discussed in the context of concrete applications (e.g. Ferrer-i-Carbonell and Frijters, 2004), there is little comparative evidence on their finite sample properties and performance that can be generalized. In the present paper, we aim to fill this gap by performing Monte Carlo simulations that yield statistical measures for consistency and efficiency for the previously mentioned alternative estimation strategies.

The contribution of the paper is twofold. First, the paper presents a systematic evaluation of the recently developed conditional binary estimators for ordered response models in finite samples, which are unknown so far. Second, the paper functions as a guide for applied researchers who typically face data for which asymptotic theory is not applicable and who need to choose between the different proposed estimation strategies.

The remainder of the paper is structured as follows: Section 1.2 revisits the proposed 
estimation strategies more formally. Section 1.3 describes the Monte Carlo experiment, including the data generating process, and presents the results of our simulations for different sample sizes, ordinal scales, number and distribution of covariates. Section 1.4 concludes.

\subsection{Estimation Strategies in Detail}

We want to estimate a latent variable model with ordered response data. The model is given by:

$$
y_{i t}^{*}=\beta^{\prime} x_{i t}+\alpha_{i}+\epsilon_{i t}
$$

where $y_{i t}^{*}$, for example, represents general well-being of individual $i=1, \ldots, I$ at time $t=1, \ldots, T$ and is a continuous variable that cannot be observed. $x_{i t}$ is a vector of independent explanatory variables, $\alpha_{i}$ is the individual personality trait assumed to be correlated with the vector of explanatory variables $x_{i t}$. Finally $\epsilon_{i t}$ is the logistically distributed error term. Since the continuous latent variable $y_{i t}^{*}$ cannot be observed, an ordered categorical response variable $y_{i t}$ is measured with $k=1, \ldots, K$ categories and individual-specific thresholds $\lambda_{k}^{i}$, where $\lambda_{k}^{i}<\lambda_{k+1}^{i}$ :

$$
y_{i t}=k \Leftrightarrow \lambda_{k}^{i} \leq y_{i t}^{*}<\lambda_{k+1}^{i} .
$$

In what follows we discuss and compare six possible estimation strategies for this ordered response problem. One simple estimation strategy for ordered response data with unobserved personality traits is to transform the ordered response variable so that it can be estimated with a conditional logit estimator (see Chamberlain, 1980). To generate the required binary response variable from ordered responses one common approach is to apply what is considered a meaningful threshold $(Y)$ to the whole data set (e.g., Winkelmann and Winkelmann, 1998; Clark, 2003) such that:

$$
B_{i t}= \begin{cases}0 & \text { if } y_{i t} \leq Y \\ 1 & \text { if } y_{i t}>Y\end{cases}
$$


The conditional logit statistic corresponding to this simple coding scheme then is:

$$
P\left[B_{i t} \mid \sum_{t} B_{i t}=c_{i}\right]=\frac{e^{\sum_{t=1}^{T} B_{i t} x_{i t} \beta}}{\sum_{y \in S\left(k_{i}, c_{i}\right)} e^{\sum_{t=1}^{T} B_{i t} x_{i t} \beta}} .
$$

This represents the probability that the dependent variable is above $Y$, conditional on the sum $c_{i}$. More precisely, $c_{i}$ denotes the number of times the dependent variable per group exceeds the threshold $Y, 0<c<T$. S describes the set of all possible combinations of $y_{i 1}, \ldots, y_{i T}$ that sum up to $\sum_{t} B_{i t}=c_{i}$. In the following, we refer to this estimation strategy as simple conditional logit (SCLOG).

Clearly the SCLOG ignores all variation in $y_{i t}$ that takes place below or above $Y$. Furthermore and most importantly, the applied simple coding scheme also abstracts from the possibility that the thresholds $\lambda_{k}^{i}$ in Equation 1.2 vary in $i$. For example, consider ordered responses on life satisfaction. Our sample may include a happy life long enthusiast and an equally happy life-long sceptic. While the enthusiast's self reported life satisfaction scores may tend to be on the high side, responses of the equally happy sceptic may tend to be on the low side. Accordingly, in this example, a common threshold crossing cannot capture changes in the self-reported life satisfaction of the sceptic and the enthusiast equally well. Thus, this strategy does not address personality traits in any satisfactory way.

A somewhat more sophisticated coding scheme takes account of such personality traits by constructing a binary response variable $(E)$ that takes the value one if the score of the ordered categorical response variable is above the individual-specific mean of all ordered categorical responses:

$$
E_{i t}= \begin{cases}0 & \text { if } y_{i t} \leq E\left(y_{i t}\right) \\ 1 & \text { if } y_{i t}>E\left(y_{i t}\right)\end{cases}
$$

To stay with the example, our enthusiast and sceptic now have different thresholds that reflect that the responses of the former tend to be on the high side of the ordered scale while the responses of the latter tend to be on the low side. Recent applications of this approach include Kassenböhmer and Haisken-DeNew (2009). In the following, we refer to this approach as individual mean conditional logit (IMCLOG).

An extension to the IMCLOG method is proposed in Ferrer-i-Carbonell and Frijters 
(2004) taking into account more variation in individuals' ordered responses. Their method uses the conditional logit approach combined with a fairly complex individualspecific coding of the dependent variable. They use the information from the second derivative of the log likelihood function, the Hessian matrix, per individual to choose which coding is appropriate for the final conditional logit estimation. This procedure consists of three steps, which deserve some detailed explanation as the exposition in the original article of Ferrer-i-Carbonell and Frijters (2004) is incomplete.

In the first step the ordered dependent variable $y_{i t}$ with $K$ categories is split into $K-1$ new binary coded variables $D_{i k}$ capturing all possible threshold crossings.

The first newly generated variable $D_{i 1}$ equals one if the original dependent variable $y_{i t}$ is at least one category greater than the minimum of $y_{i t}$ for each $i$ :

$$
D_{i t k}= \begin{cases}0 & \text { if } y_{i t} \leq \min _{i}\left\{y_{i t}\right\} \\ 1 & \text { if } y_{i t}>\min _{i}\left\{y_{i t}\right\}\end{cases}
$$

The next newly generated variable $D_{i 2}$ equals one if the original dependent variable is at least two categories greater than the minimum of $y_{i t}$ for each $i$ and so forth. A more detailed example can be found in the appendix of Ferrer-i-Carbonell and Frijters (2004).

In a second step, a conditional logit model (Chamberlain, 1980) is estimated for the first threshold crossing to derive the coefficients $(\beta)$ that are used to calculate the Hessian matrix for each individual for each $D_{i k}$.

The first and second derivatives of the log likelihood function used for these calculations can be found in the appendix to this paper. On this basis, the sum of the diagonal elements, the so called "trace," for each individual Hessian is calculated for each $D_{i k}$. The final binary dependent variable is then generated by choosing the specific $D_{i k}$ that corresponds to the minimum trace per individual $i$. Since the variance of the estimated conditional logit coefficient is the negative of the inverse of the sum of the Hessian $H_{i}$ over all $i$, this yields the maximum likelihood estimator with minimal variance.

In a third step, the newly generated binary variable, which reflects the optimal choice of $D_{i k}$ for all $i$, is fed into a conditional logit estimation to obtain the final coefficients. In the following, we refer to this estimation strategy as the Ferrer-i-Carbonell 
Frijters estimator (FCF). Since the FCF estimator requires calculation of individualspecific Hessian matrices for each possible threshold $D_{i k}$, it is computationally expensive, particularly if $T$ is large $2^{2}$

Note that the individual-specific coding procedure based on minimum-trace individual Hessian matrices is initially based on the assumption of knowing the true parameter estimates of the latent variable model. It is debatable how these initial parameters should be obtained. We test whether the FCF estimation results differ when using the individual mean coding procedure (IMCLOG), i.e., whether the FCF estimates are sensitive to replacing $D_{i t 1}$ with $E_{i t}$ from Equation 1.5 . Furthermore, we also estimate an iterated version of the FCF, continuously updating the initial parameters. However, there are only subtle differences between the corresponding final FCF parameters. Thus, the FCF method is robust with respect to the choice of the first-step estimation routine.

Yet, an alternative recoding scheme is introduced in Baetschmann et al. (2011). Their so called "Blow-Up and Cluster" (BUC) estimator recodes the original dependent variable with $k$ categories into $k-1$ different dichotomizations using $k-1$ different thresholds. Each observation of the original data is then duplicated $k-1$ times, one for each dichotomization. After "blowing up" the data, a standard conditional logit estimation with clustered standard errors is applied to the whole sample. For more details we refer to the paper of Baetschmann et al. (2011).

Finally, we consider the linear fixed effects model that assumes cardinality and makes use of all variation in individuals' ordered responses, while also accounting for non-random personality traits. The ordered response categories $k=1, \ldots, K$ of $y_{i t}$ are interpreted as continuous values of the latent variable $y *_{i t}$, which lends itself to linear regression methods. Personality traits can be addressed by, for instance, withintransformation of Equation 1.1, such that $\alpha_{i}$ cancels out:

$$
y_{i t}^{*}-\bar{y}_{i t}^{*}=\beta^{\prime}\left(x_{i t}-\bar{x}_{i t}\right)+\epsilon_{i t}-\bar{\epsilon}_{i t}
$$

In the following we refer to this estimation strategy as the fixed effects estimator

\footnotetext{
${ }^{2}$ For example, a data setup of 3,000 individuals with 15 observations over time can take about half an hour computation time.
} 
(FE) $3^{3}$ The FE has the advantage that it is fast and very easy to implement. However, assuming cardinality of ordered responses may be an assumption yielding biased estimates. Nevertheless, as previously discussed, numerous studies have used this approach (e.g., Scheve and Slaughter, 2004; Di Tella et al., 2001, Senik, 2004) and at least in the context of life satisfaction studies, there is some evidence that the associated bias is only moderate (Ferrer-i-Carbonell and Frijters, 2004). Additionally, Greene (1981), Chung and Goldberger (1984) or Deaton and Irish (1984) theoretically show that, under certain distributional assumptions of the explanatory variables, coefficient estimates of limited dependent variable and discrete choice models using OLS can be consistent up to a scalar multiple. If this is also the case for linearly estimated ordered response models with fixed effects, coefficient ratios of OLS estimates should be consistent as well.

A mild alteration to the FE method is proposed in van Praag and Ferrer-i-Carbonell (2008). Their probit adapted OLS estimator (POLS) attempts to cardinalize the data such that it can be applied to simple OLS without the aforementioned problems of the FE estimator and has been used in e.g., Stevenson and Wolfers (2008), Luechinger (2009), Luechinger et al. (2010). The POLS estimator attempts to circumvent violations of the cardinality assumption by first calculating the relative frequencies of the different outcome categories and then putting the frequencies into a standard normal distribution function to obtain a standard normal distributed, "cardinal scaled", and unbounded dependent variable. This variable can be used then for simple (fixed effect) OLS. For more details on this procedure, see Chapter 2.6 in van Praag and Ferrer-i-Carbonell (2008).

Regardless, from a theoretical perspective, assuming cardinality of ordered responses may be unsatisfactory, and our Monte Carlo simulations will show whether this pragmatic approach frequently employed in the life satisfaction literature is justified in a more general setting.

\footnotetext{
${ }^{3}$ First difference transformation of the model yields equivalent results.
} 


\subsection{Monte Carlo simulation and results}

For some of the analysed estimation strategies asymptotic properties have been theoretically proven in the literature, other namely the FCF, IMCLOG and BUC still have unknown asymptotic properties. Regardless, for the applied researcher finite sample properties are important when choosing between different estimation strategies. We therefore perform Monte Carlo simulations for all estimators discussed in Section 1.2 to provide a guideline for when which estimation strategy is appropriate. We also consider the standard ordered logit without unobserved personality traits controls for comparison. All simulations are performed 1000 times for different sample sizes, ordinal scales, number and distribution of covariates 4 Our data generating process is designed in line with the standard Monte Carlo simulation literature for panel data (e.g., Honoré and Kyriazidou, 2000; Greene, 2004). The latent variable $y_{i t}^{*}$ is generated by the following model:

$$
y_{i t}^{*}=x_{i t} \beta+\alpha_{i}+\epsilon_{i t}
$$

The individual fixed effect $\alpha_{i}$ is generated as $\alpha_{i}=\sqrt{T} \bar{x}_{i}$. The idiosyncratic error $\epsilon_{i t}$ is i.i.d. logistically distributed, and the exogenous variables $x_{i t}$ are i.i.d. normally distributed. Both error and exogenous variables have the same standard deviation of $\sigma=\pi / \sqrt{3}$. As a robustness check we later consider alternative symmetric and asymmetric distributions of $x_{i t}$.

We define the categories for the discrete dependent variable $y_{i t}$ by splitting the generated latent variable $y_{i t}^{*}$ into $K$ even parts. As a result, every category has the same number of observations. To evaluate how the different estimates converge to the true parameters, we focus on the mean of the estimated coefficients, the mean squared error (MSE), and as a more robust performance measure to possible outliers, the median absolute error (MAE). We also compare efficiency measures like the mean of the coefficients' standard errors (S.E.) as well as associated 95 per cent confidence intervals across simulations.

\footnotetext{
${ }^{4} \mathrm{We}$ use the statistical software STATA to run our simulations. The corresponding STATA ado-file for the FCF estimator can be downloaded from the following website: http://hdl.handle.net/11022/0000-0000-1F7A-6.
} 
Table 1.1: Monte Carlo simulation results for $K=3, T=5$

$$
\beta=1
$$

Mean S.E. MSE MAE $95 \%$ Interval

\begin{tabular}{rllllll}
\hline $\mathbf{I}=\mathbf{1 0 0}$ & \multicolumn{1}{c}{} \\
\hline FE OLS & 0.20526 & 0.01416 & & & & \\
POLS & 0.22324 & 0.01540 & & & & \\
ordered logit & 1.03623 & 0.06999 & 0.00671 & 0.05192 & 0.89769 & 1.20035 \\
SCLOG & 1.01140 & 0.14563 & 0.02093 & 0.09346 & 0.76928 & 1.32656 \\
FCF & 0.98475 & 0.11516 & 0.02538 & 0.08207 & 0.78009 & 1.24946 \\
IMCLOG & 0.98594 & 0.11772 & 0.01531 & 0.07952 & 0.78337 & 1.25336 \\
BUC & 1.00708 & 0.10682 & 0.01238 & 0.06708 & 0.80646 & 1.25820
\end{tabular}

\begin{tabular}{rllllll}
\hline I = 500 & & & & & & \\
\hline FE OLS & 0.20555 & 0.00632 & & & & \\
POLS & 0.22355 & 0.00687 & & & & \\
ordered logit & 1.03423 & 0.03124 & 0.00215 & 0.03322 & 0.97628 & 1.10259 \\
SCLOG & 1.00433 & 0.06419 & 0.00446 & 0.04419 & 0.88182 & 1.14270 \\
FCF & 0.97926 & 0.05102 & 0.00314 & 0.03892 & 0.88404 & 1.08702 \\
IMCLOG & 0.98090 & 0.05218 & 0.00310 & 0.03846 & 0.88357 & 1.08989 \\
BUC & 1.00330 & 0.04780 & 0.00242 & 0.03409 & 0.91493 & 1.11028 \\
& & & & & & \\
\hline I = 1000 & & & & & & \\
\hline FE OLS & 0.20477 & 0.00446 & & & & \\
POLS & 0.22270 & 0.00485 & & & & \\
ordered logit & 1.03298 & 0.02206 & 0.00163 & 0.00840 & 0.98943 & 1.07798 \\
SCLOG & 1.00183 & 0.04529 & 0.00225 & 0.03235 & 0.91389 & 1.09804 \\
FCF & 0.97711 & 0.03600 & 0.00193 & 0.03270 & 0.91003 & 1.05655 \\
IMCLOG & 0.97921 & 0.03684 & 0.00191 & 0.03224 & 0.90987 & 1.06044 \\
BUC & 1.00080 & 0.03390 & 0.00124 & 0.02508 & 0.93906 & 1.07563 \\
& & & & & & \\
\hline I = 3000 & & & & & & \\
\hline FE OLS & 0.20492 & 0.00258 & & & & \\
POLS & 0.22286 & 0.00280 & & & & \\
FCOF & 0.97514 & 0.02073 & 0.00103 & 0.02561 & 0.93725 & 1.01506 \\
BUC & 0.99912 & 0.01953 & 0.00037 & 0.01362 & 0.96365 & 1.03747 \\
& & & & & & \\
\hline SCOG & 0.99857 & 0.02603 & 0.00064 & 0.01767 & 0.95139 & 1.05082 \\
\hline logit & 1.03253 & 0.01275 & 0.00122 & 0.00835 & 1.00751 & 1.05610 \\
& & & & & & \\
\hline
\end{tabular}

Note: All simulations were performed 1000 times. 
We start with only one exogenous variable $x_{i t}$ and set the coefficient to $\beta=1$. To compare the asymptotic properties of the estimators under consideration we start with a small panel and subsequently increase the cross-sectional and longitudinal dimension sizes. Table 1.1 presents estimation results where we fix the longitudinal dimension to $T=5$ and raise the cross-sectional dimension size from $I=100$ to $I=3,000$ while $K=3$.

In accordance with asymptotic theory, all nonlinear estimators except IMCLOG and FCF and of course the standard ordered logit converge towards the true parameter with growing precision with increasing $I$. When instead evaluating asymptotic properties over $t$, as reported in Table $1.2^{5}$ we see in our simulations that the coefficient estimates converges towards the true parameter for all nonlinear estimators except the standard ordered logit. Unsurprisingly, the class of linear estimators (FE and POLS) cannot provide consistent estimates of the true parameter due to the the different functional form of the probability function. As a consequence, with only one explanatory variable, the FE and POLS cannot be compared with the other estimators, and we do not report performance measures other than the mean coefficients and standard errors. However, when later including more than one explanatory variable, we will compare the coefficient ratios to reflect on the relative size of coefficients.

In what follows we look at the speed with which convergence of the different nonlinear estimators is achieved and how severe the bias of inconsistent estimators is. Ignoring unobserved individual heterogeneity clearly biases coefficient estimates for all panel data configurations. In Table 1.1 and Table 1.2 the means of the simple ordered logit coefficients are always furthest away from the true parameter $\beta=1$. These simulation results are in line with Ferrer-i-Carbonell and Frijters (2004) who stress the importance of allowing for individual fixed effects.

Comparing the consistent nonlinear models SCLOG and BUC leads to several important insights. First of all, the simple binary coding procedure SCLOG is very sensitive to small sample sizes because it already disregards a large part of the available variation in the dependent variable ${ }^{6}$ For example, with $T=5$ and $I=100$,

\footnotetext{
${ }^{5}$ We also perform simple t-tests to compare the means of the respective estimators' coefficients when $I$ and $T$ increase. The differences of the means are statistically significant when starting from small $T$ and small $I$ and become insignificant when both dimension sizes are large.

${ }^{6}$ For our data set with $y_{i t} \in\{1,2,3\}$ we did the following binary recoding: $y_{i t}^{n}=1$, if $y_{i t}>2$.
} 
Table 1.2: Monte Carlo simulation results for $K=3, I=1000$

$$
\beta=1
$$

Mean S.E. MSE MAE $95 \%$ Interval

\begin{tabular}{rllllll}
\hline T $=\mathbf{3}$ & & & & & & \\
\hline FE OLS & 0.19821 & 0.00620 & & & & \\
POLS & 0.21557 & 0.00674 & & & & \\
ordered logit & 1.17846 & 0.03299 & 0.03296 & 0.17729 & 1.11813 & 1.24220 \\
SCLOG & 1.00044 & 0.07233 & 0.00544 & 0.04885 & 0.86150 & 1.15537 \\
FCF & 0.96420 & 0.05460 & 0.00424 & 0.04818 & 0.86095 & 1.07516 \\
IMCLOG & 0.97921 & 0.05570 & 0.00427 & 0.04775 & 0.85826 & 1.08004 \\
BUC & 0.99988 & 0.05383 & 0.00286 & 0.03576 & 0.89692 & 1.10606
\end{tabular}

\begin{tabular}{rllllll}
\hline T = 5 & & & & & & \\
\hline FE OLS & 0.20555 & 0.00632 & & & & \\
POLS & 0.22355 & 0.00687 & & & & \\
ordered logit & 1.03423 & 0.03124 & 0.00215 & 0.03322 & 0.97628 & 1.10259 \\
SCLOG & 1.00433 & 0.06419 & 0.00446 & 0.04419 & 0.88182 & 1.14270 \\
FCF & 0.97926 & 0.05102 & 0.00314 & 0.03892 & 0.88404 & 1.08702 \\
IMCLOG & 0.98090 & 0.05218 & 0.00310 & 0.03846 & 0.88357 & 1.08989 \\
BUC & 1.00330 & 0.04780 & 0.00242 & 0.03409 & 0.91493 & 1.11028 \\
& & & & & & \\
\hline T = 10 & & & & & & \\
FE OLS & 0.21262 & 0.00304 & & & & \\
POLS & 0.23124 & 0.00330 & & & & \\
ordered logit & 0.90834 & 0.01379 & 0.00859 & 0.09168 & 0.88139 & 0.93454 \\
SCLOG & 0.99986 & 0.02741 & 0.00074 & 0.01834 & 0.94901 & 1.05545 \\
FCF & 0.98763 & 0.02310 & 0.00070 & 0.01823 & 0.94010 & 1.03268 \\
IMCLOG & 0.98774 & 0.02343 & 0.00071 & 0.01835 & 0.93772 & 1.03382 \\
BUC & 0.99917 & 0.02063 & 0.00043 & 0.01415 & 0.95767 & 1.04011 \\
& & & & & & \\
\hline T = 15 & & & & & & \\
\hline IMCLOG & 0.99116 & 0.01858 & 0.00044 & 0.01507 & 0.95451 & 1.02742 \\
BUC & 0.99956 & 0.01614 & 0.00028 & 0.01139 & 0.96684 & 1.03459 \\
FE OLS & 0.21602 & 0.00246 & & & & \\
POLS & 0.23493 & 0.00267 & & & & \\
SCLOG & 1.00004 & 0.02135 & 0.00050 & 0.01496 & 0.95837 & 1.04591 \\
\hline orded logit & 0.85903 & 0.01103 & 0.01999 & 0.14065 & 0.83816 & 0.88044 \\
\hline & & & & & & \\
\hline
\end{tabular}

Note: All simulations were performed 1000 times. 
40 percent of all observations were ignored because of no variation in the dependent variable. With real survey data and less homogeneous categories, the loss of variation may be even more serious. We therefore recommend not using the SCLOG method in small samples.

Of all estimators the BUC method dominates in terms of consistency and efficiency measures for all panel data configurations. Through all our simulations the mean of estimated parameters is closest to the true value $\beta=1$ with the lowest MSE and MAE. At the same time the mean standard error of $\beta$ and the associated confidence interval is smallest. As a first conclusion, these simulations clearly show the asymptotic properties of the estimation methods: Only the SCLOG and BUC estimates can be considered as unbiased while the BUC is most efficient.

We proceed by comparing the set of estimators when including more than one explanatory variable in the model, which is more informative for the applied researcher. Table 1.3 reports the performance measures for the coefficient with three explanatory variables. In applied research, coefficient ratios are frequently employed to interpret the size of coefficients relative to a baseline effect. In the analysis of individual wellbeing, for instance, it is common to calculate compensating income variations, i.e., the well-being effect of certain events expressed in percentage changes in income that would generate the same well-being effect (see Winkelmann and Winkelmann, 1998). Accordingly, it is not necessarily the absolute size of coefficients that researchers are interested in, but their ratios.

For the following simulation, we arbitrarily set total number of observations to 18,000 consisting of $I=3000$ and $T=6$, a sample structure not uncommon in micro data. We choose $\beta_{1}=1, \beta_{2}=-3.5$ and $\beta_{3}=7$ as the true data generating parameters so we can also evaluate the correct sign of the parameter estimates as well as their ratios $\beta_{2} / \beta_{1}=-3.5$ and $\beta_{3} / \beta_{1}=7$.

As previously argued, the coefficients of the linear fixed effects models (FE, POLS) cannot be compared to the ones from nonlinear estimators due to the different scaling. However, as becomes apparent in Table 1.3 the estimated coefficient ratios of the FE, as well as the ratios of the POLS, are very close to the ratios of the true parameters, i.e., $\widehat{\beta_{2}} / \widehat{\beta_{1}}$ is almost exactly -3.5 and $\widehat{\beta_{3}} / \widehat{\beta}_{1}$ is nearly 7 . At the same time, of all estimators, 
Table 1.3: Monte Carlo simulation results for $K=3, I=3000, T=6$

\begin{tabular}{|c|c|c|c|c|c|}
\hline & \multicolumn{5}{|c|}{$\beta_{2} / \beta_{1}=-3.5$} \\
\hline & Mean & MSE & MAE & \multicolumn{2}{|c|}{$95 \%$ Interval } \\
\hline FE OLS & -3.50254 & 0.01688 & 0.09059 & -3.77135 & -3.26882 \\
\hline POLS & -3.50255 & 0.01688 & 0.09047 & -3.77223 & -3.26900 \\
\hline ordered logit & -2.96128 & 0.29334 & 0.54159 & -3.07308 & -2.85501 \\
\hline SCLOG & -3.50610 & 0.03664 & 0.12148 & -3.92625 & -3.16180 \\
\hline FCF & -3.50022 & 0.01837 & 0.08657 & -3.78670 & -3.23716 \\
\hline IMCLOG & -3.50289 & 0.02615 & 0.10578 & -3.85568 & -3.21248 \\
\hline \multirow[t]{3}{*}{ BUC } & -3.49951 & 0.01807 & 0.08461 & -3.78585 & -3.24382 \\
\hline & \multicolumn{5}{|c|}{$\boldsymbol{\beta}_{3} / \boldsymbol{\beta}_{1}=7$} \\
\hline & Mean & MSE & MAE & \multicolumn{2}{|c|}{ 95\% Interval } \\
\hline FE OLS & 7.00921 & 0.06358 & 0.17499 & 6.55400 & 7.54091 \\
\hline POLS & 7.00924 & 0.06358 & 0.17470 & 6.55289 & 7.54045 \\
\hline ordered logit & 6.28513 & 0.52405 & 0.71975 & 6.07888 & 6.51445 \\
\hline SCLOG & 7.01410 & 0.13999 & 0.24292 & 6.33485 & 7.85700 \\
\hline FCF & 7.00274 & 0.06840 & 0.17344 & 6.51613 & 7.55918 \\
\hline IMCLOG & 7.00530 & 0.09721 & 0.19735 & 6.43982 & 7.68614 \\
\hline BUC & 7.00133 & 0.06733 & 0.17449 & 6.52065 & 7.54664 \\
\hline
\end{tabular}

the MSE and the MAE of the FE and the POLS are smallest.7

Of all the nonlinear estimators controlling for unobserved heterogeneity in Table 1.3 . both the BUC and the FCF method outperform the others in terms of unbiasedness and efficiency of coefficient ratio estimates. Compared to the SCLOG and the IMCLOG, the means of the BUC and FCF parameter estimates come closest to the true parameters in conjunction with the smallest standard errors and lowest values for MSE and MAE. In comparison, ignoring unobserved individual heterogeneity by applying the simple ordered logit estimator leads to severely biased coefficient ratios in Table 1.3 . This becomes apparent when looking at the 95 per cent interval of the ordered logit estimates, in which the true parameters are not included, and the large MAE.

We also check the performance of the alternative estimation strategies for different distributions of the explanatory variables. Table 1.4 shows Monte Carlo simulations for left and right skewed Beta distributions as well as for normal distributions with different first and second moments. In general, when departing from the standard

\footnotetext{
${ }^{7}$ Furthermore, our simulations for increasing samples sizes (not reported) indicate that the FE and POLS deliver in fact consistent estimates of parameter ratios.
} 
Table 1.4: Monte Carlo simulation results for different distributions of the explanatory variables

$\boldsymbol{x}_{\mathbf{1}} \sim \operatorname{Beta}(\mathbf{1}, \mathbf{5}), \boldsymbol{x}_{\mathbf{2}} \sim \operatorname{Beta}(\mathbf{2}, \mathbf{2}), \boldsymbol{x}_{\mathbf{3}} \sim \operatorname{Beta}(\mathbf{5}, \mathbf{1})$

\begin{tabular}{rcccccc} 
& \multicolumn{2}{c}{$\boldsymbol{\beta}_{\mathbf{2}} / \boldsymbol{\beta}_{\mathbf{1}}=-\mathbf{3 . 5}$} & \multicolumn{2}{c}{$\boldsymbol{\beta}_{\mathbf{3}} / \boldsymbol{\beta}_{\mathbf{1}}=\mathbf{7}$} & \multicolumn{2}{c}{$\boldsymbol{\beta}_{\mathbf{3}} / \boldsymbol{\beta}_{\mathbf{2}}=-\mathbf{2}$} \\
Method & Mean & MSE & Mean & MSE & Mean & MSE \\
\hline FE OLS & -3.69695 & 0.78830 & 7.01602 & 2.67229 & -1.89997 & 0.01798 \\
POLS & -3.69685 & 0.78805 & 7.01293 & 2.66892 & -1.89918 & 0.01812 \\
SCLOG & -3.71210 & 1.26982 & 7.42891 & 5.07450 & -2.00496 & 0.01442 \\
FCF & -3.68803 & 1.19382 & 7.39570 & 4.74821 & -2.00864 & 0.01240 \\
IMCLOG & -3.69735 & 1.09772 & 7.39250 & 4.29584 & -2.00282 & 0.01260 \\
BUC & -3.63606 & 0.76707 & 7.27752 & 3.05166 & -2.00384 & 0.00940
\end{tabular}

$\boldsymbol{x}_{\mathbf{1}} \sim \operatorname{Normal}(\mathbf{0}, \mathbf{1}), \boldsymbol{x}_{\mathbf{2}} \sim \operatorname{Normal}(\mathbf{5}, \mathbf{1 0}), \boldsymbol{x}_{\mathbf{3}} \sim \operatorname{Normal}(\mathbf{2}, \mathbf{0 . 1})$

\begin{tabular}{rrrrrrr} 
& \multicolumn{2}{c}{$\boldsymbol{\beta}_{\mathbf{2}} / \boldsymbol{\beta}_{\mathbf{1}}=-\mathbf{3 . 5}$} & \multicolumn{2}{c}{$\boldsymbol{\beta}_{\mathbf{3}} / \boldsymbol{\beta}_{\mathbf{1}}=\mathbf{7}$} & \multicolumn{2}{c}{$\boldsymbol{\beta}_{\mathbf{3}} / \boldsymbol{\beta}_{\mathbf{2}}=-\mathbf{2}$} \\
Method & Mean & MSE & \multicolumn{1}{c}{ Mean } & MSE & Mean & MSE \\
\hline FE OLS & -3.74551 & 1.32221 & 7.42532 & 11.96346 & -1.99623 & 0.51903 \\
POLS & -3.74530 & 1.32103 & 7.42451 & 11.95713 & -1.99613 & 0.51894 \\
SCLOG & -4.37796 & 35.83729 & 8.19181 & 256.44650 & -1.89413 & 1.19050 \\
FCF & -3.81028 & 1.91946 & 7.39687 & 17.39827 & -1.93452 & 0.57558 \\
IMCLOG & -3.98390 & 17.75278 & 7.49777 & 96.14915 & -1.93663 & 0.94279 \\
BUC & -3.80662 & 1.91339 & 7.36381 & 17.26725 & -1.92684 & 0.57119
\end{tabular}

$\boldsymbol{x}_{\mathbf{1}} \sim \operatorname{Normal}(\mathbf{0}, \mathbf{1}), \boldsymbol{x}_{\mathbf{2}} \sim \operatorname{Normal}(\mathbf{0}, \mathbf{2}), \boldsymbol{x}_{\mathbf{3}} \sim \operatorname{Normal}(\mathbf{0}, \mathbf{3})$

\begin{tabular}{rcccccc} 
& \multicolumn{2}{c}{$\boldsymbol{\beta}_{\mathbf{2}} / \boldsymbol{\beta}_{\mathbf{1}}=-\mathbf{3 . 5}$} & \multicolumn{2}{c}{$\boldsymbol{\beta}_{\mathbf{3}} / \boldsymbol{\beta}_{\mathbf{1}}=\mathbf{7}$} & \multicolumn{2}{c}{$\boldsymbol{\beta}_{\mathbf{3}} / \boldsymbol{\beta}_{\mathbf{2}}=-\mathbf{2}$} \\
Method & Mean & MSE & Mean & MSE & Mean & MSE \\
\hline FE OLS & -3.59997 & 0.51341 & 7.20573 & 2.06420 & -2.00254 & 0.00271 \\
POLS & -3.59987 & 0.51328 & 7.20553 & 2.06373 & -2.00255 & 0.00271 \\
SCLOG & -3.74290 & 1.34155 & 7.48449 & 5.29469 & -2.00199 & 0.00547 \\
FCF & -3.63117 & 0.54875 & 7.26366 & 2.19126 & -2.00103 & 0.00273 \\
IMCLOG & -3.68796 & 0.82737 & 7.37118 & 3.29663 & -1.99967 & 0.00371 \\
BUC & -3.62824 & 0.54313 & 7.25735 & 2.16254 & -2.00097 & 0.00270
\end{tabular}

Monte Carlo simulation results for $I=1000, T=6, K=3$.

All simulations were performed 1000 times. 
normal distribution the bias of estimated coefficient ratios increases. However, we still infer that the FE, POLS, BUC and FCF deliver coefficient ratio estimates with small bias.

So far we have assumed that the ordinal response variable is fairly aggregated and lies on a three-point scale $(K=3)$. However, various ordinal scales consist of more than three categories. For example, in the U.S. National Survey of Families and Households (NSFH) and the German Socio-Economic Panel (SOEP), information on individual well-being is captured on a seven- and eleven-point scale, respectively. Against this backdrop, we want to test the extent to which the performance of the estimators under consideration varies with respect to the ordinal structure of the dependent variable. Table 1.5 lists the simulation results for a three-, seven- and eleven-point scale ordered response variable. All simulations are performed with two exogenous variables with the true parameters $\beta_{1}=1$ and $\beta_{2}=-2$. The panel data dimensions are $I=3,000$ and $T=128$ Interestingly, it seems that the IMCLOG and FCF method respond rather sensitively to the number of ordered categories in the dependent variable. With increasing $K$ the estimated parameters show a sizeable downward bias, although the $\beta_{2} / \beta_{1}=-2$ ratios remain unbiased. This confirms Baetschmann et al. (2011) who have recently shown, that the estimation strategies of Ferrer-i-Carbonell and Frijters (2004) of which IMCLOG can be considered a special case can produce biased parameter estimates. The reason behind is an endogeneity problem of the individual threshold, which is by itself a function of the original ordered variable. In comparison, BUC, and SCLOG are not sensitive with respect to the size of $K$; there is no significant change in the mean of the parameter estimates, the MSE, MAE or in the the mean standard error. In terms of coefficient ratios, all nonlinear estimates are unbiased as long unobserved personality traits are controlled for, irrespective of $K$. The same holds for the linear class of estimators FE and POLS.

Summarizing our simulation results, we find the BUC estimator to perform best, that is to deliver unbiased and efficient parameter estimates irrespective of sample size, the underlying distribution of $x_{i t}$ and the number of ordinal response categories. In addition, for large samples the SCLOG estimator also performs well and may be even

\footnotetext{
${ }^{8}$ To accommodate higher $K$ it is necessary to have more observations per individual. We therefore increase the number of time periods from $T=6$ in Table 1.3 to $T=12$.
} 
easier to implement.

However, if the researcher is only interested in relative parameters, all of the above estimators deliver unbiased parameter ratios as long as unobserved personality traits are controlled for. This finding also relates to a large theoretical literature that proves that even with misspecified nonlinear models one can obtain consistent coefficient ratio estimates (see e.g., Ruud, 1983; Cramer, 2007 and Wooldridge, 2010).

Furthermore, our Monte Carlo simulations show that to obtain unbiased estimates of parameter ratios one can also employ simple linear estimation allowing for individual fixed effects. This is a generalization of a familiar result derived in the context of happiness studies (e.g., Ferrer-i-Carbonell and Frijters, 2004). The result also relates to Greene (1981), Chung and Goldberger (1984) or Deaton and Irish (1984) who demonstrate that under certain distributional assumptions one can obtain consistent parameter ratio estimates by applying OLS to discrete choice problems. 
Table 1.5: Monte Carlo simulation results for $I=3000, T=12$

$$
\beta_{1}=1
$$

Mean S.E. MSE MAE $95 \%$ Interval

\begin{tabular}{rllllll}
\hline K = 3 & & & & & & \\
\hline FE OLS & 0.16148 & 0.00248 & & & & \\
POLS & 0.17563 & 0.00270 & & & & \\
ordered logit & 0.92901 & 0.01586 & 0.00529 & 0.07188 & 0.89849 & 0.96411 \\
SCLOG & 0.99994 & 0.02903 & 0.00090 & 0.01946 & 0.94103 & 1.06088 \\
FCF & 0.99330 & 0.02656 & 0.00074 & 0.01819 & 0.94225 & 1.04474 \\
IMCLOG & 0.98699 & 0.02651 & 0.00094 & 0.02148 & 0.93630 & 1.04430 \\
BUC & 0.99976 & 0.02110 & 0.00045 & 0.01412 & 0.96138 & 1.04181 \\
& & & & & & \\
K = 7 & & & & & & \\
FE OLS & 0.42420 & 0.00500 & & & & \\
POLS & 0.20693 & 0.00235 & & & & \\
ordered logit & 0.92531 & 0.01208 & 0.00572 & 0.07466 & 0.90169 & 0.94856 \\
SCLOG & 0.99972 & 0.02784 & 0.00075 & 0.01826 & 0.94528 & 1.05358 \\
FCF & 0.95820 & 0.02539 & 0.00239 & 0.04203 & 0.90878 & 1.00931 \\
IMCLOG & 0.99042 & 0.02635 & 0.00080 & 0.01979 & 0.93930 & 1.04363 \\
BUC & 0.99932 & 0.01645 & 0.00026 & 0.01100 & 0.96783 & 1.03000 \\
& & & & & & \\
\hline K = 11 & & & & & & \\
FE OLS & 0.67823 & 0.00761 & & & & \\
POLS & 0.21344 & 0.00225 & & & & \\
ordered logit & 0.92525 & 0.01138 & 0.00573 & 0.07483 & 0.90294 & 0.94886 \\
SCLOG & 0.99906 & 0.02766 & 0.00078 & 0.01933 & 0.94290 & 1.05466 \\
FCF & 0.93817 & 0.02481 & 0.00449 & 0.06286 & 0.89028 & 0.99085 \\
IMCLOG & 0.98989 & 0.02628 & 0.00081 & 0.01933 & 0.93778 & 1.03975 \\
BUC & 0.99942 & 0.01575 & 0.00027 & 0.01090 & 0.96750 & 1.03096
\end{tabular}

$$
\beta_{2}=-2
$$

Mean S.E. MSE MAE 95\% Interval

\begin{tabular}{rllllll}
\hline K $=\mathbf{3}$ & \multicolumn{1}{c}{} \\
\hline FE OLS & -0.32337 & 0.00248 & & & & \\
POLS & -0.35169 & 0.00269 & & & & \\
ordered logit & -1.50856 & 0.02589 & 0.24219 & 0.49096 & -1.56013 & -1.45887 \\
SCLOG & -2.00233 & 0.04700 & 0.00242 & 0.03288 & -2.10216 & -1.90702 \\
FCF & -1.98814 & 0.04479 & 0.00226 & 0.03063 & -2.07914 & -1.89968 \\
IMCLOG & -1.97595 & 0.04291 & 0.00265 & 0.03646 & -2.06764 & -1.89027 \\
BUC & -2.00110 & 0.03390 & 0.00124 & 0.02316 & -2.07578 & -1.93391
\end{tabular}

\begin{tabular}{rllllll}
\hline K $=\mathbf{7}$ & & & & & & \\
\hline FE OLS & -0.84926 & 0.00500 & & & & \\
POLS & -0.41421 & 0.00235 & & & & \\
ordered logit & -1.50239 & 0.02181 & 0.24808 & 0.49766 & -1.54547 & -1.46093 \\
SCLOG & -2.00188 & 0.04511 & 0.00197 & 0.02853 & -2.09208 & -1.91451 \\
FCF & -1.91857 & 0.04403 & 0.00865 & 0.08329 & -2.01559 & -1.83207 \\
IMCLOG & -1.98281 & 0.04264 & 0.00213 & 0.03225 & -2.06524 & -1.89991 \\
BUC & -1.99984 & 0.02595 & 0.00070 & 0.01730 & -2.05347 & -1.94883 \\
& & & & & & \\
\hline K = 11 & & & & & & \\
FE OLS & -1.35736 & 0.00761 & & & & \\
POLS & -0.42709 & 0.00225 & & & & \\
ordered logit & -1.50084 & 0.02107 & 0.24960 & 0.49944 & -1.54128 & -1.45818 \\
SCLOG & -2.00034 & 0.04480 & 0.00201 & 0.02971 & -2.08792 & -1.91651 \\
FCF & -1.87649 & 0.04313 & 0.01711 & 0.12460 & -1.96627 & -1.79364 \\
IMCLOG & -1.98237 & 0.04254 & 0.00219 & 0.03074 & -2.06710 & -1.89292 \\
BUC & -1.99987 & 0.02479 & 0.00067 & 0.01746 & -2.05021 & -1.94826
\end{tabular}

continued on next page... 
Table 1.5: ... continued

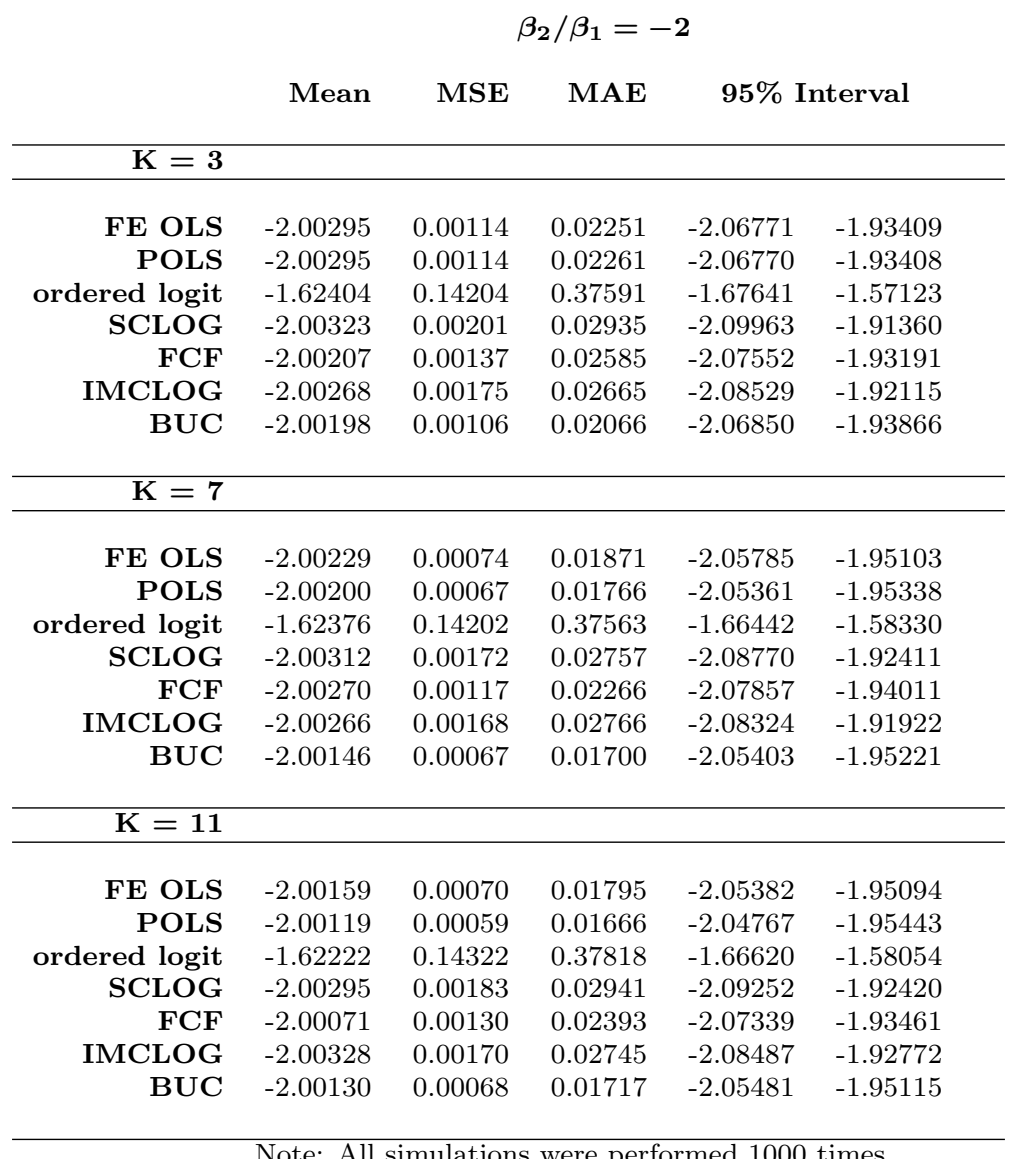

\subsection{Conclusion}

We compare linear and nonlinear ordered response estimators in terms of consistency and efficiency measures by running Monte Carlo simulations while varying the sample size, the number and distribution of covariates, and the number of ordinal response categories. The estimators under consideration are linear fixed effects, probit adapted OLS, simple ordered logit, and four binary recoded conditional logit estimators that recently have gained popularity in applied research.

Our simulations indicate that first of all it is crucial to control for individual unobserved heterogeneity. Failing to do so adds considerable bias to estimates of parameters and parameter ratios. If the researcher is interested in the absolute size of parameter estimates as such the best choice for estimating ordered response models is the newly developed "Blow-Up and Cluster" estimator of Baetschmann et al. (2011). It delivers most unbiased and most efficient parameter estimates, irrespective of sample size and 
number of ordinal response categories. The simple conditional logit estimator is an even more basic alternative but only appropriate for large samples.

However, if the researcher is mainly interested in relative effects, i.e. in ratios of parameter estimates, the method of choice is simple: a linear fixed effects model. It essentially delivers the same results as the more elaborate binary recoding scheme of Baetschmann et al. (2011) and is most efficient and much easier to compute. 


\subsection{Appendix}

Loglikelihood equation of the conditional logit model:

$$
\ln L_{i k}=\sum_{t=1}^{T} D_{i t k} x_{i t} \beta-\ln \sum_{S\left(\sum_{t=1}^{T} D_{i t k}\right)} e^{\sum_{t=1}^{T} D_{i t k} x_{i t} \beta}
$$

Gradient function of the conditional logit model:

$$
\frac{\partial \ln L_{i k}}{\partial \beta}=\sum_{t=1}^{T} D_{i t k} x_{i t}-\frac{\sum_{S\left(\sum_{t=1}^{T} D_{i t k}\right)}\left(\sum_{t=1}^{T} D_{i t k} x_{i t}\right) e^{\sum_{t=1}^{T} D_{i t k} x_{i t} \beta}}{\sum_{S\left(\sum_{t=1}^{T} D_{i t k}\right)} e^{\sum_{t=1}^{T} D_{i t k} x_{i t} \beta}}
$$

Hessian function of the conditional logit model:

$$
\begin{gathered}
H=\frac{\partial^{2} \ln L_{i k}}{\partial \beta^{2}} \\
H=\frac{\left(\sum_{S\left(\sum_{t=1}^{T} D_{i t k}\right)}\left(\sum_{t=1}^{T} D_{i t k} x_{i t}\right) e^{\sum_{t=1}^{T} D_{i t k} x_{i t} \beta}\right)\left(\sum_{S\left(\sum_{t=1}^{T} D_{i t k}\right)}\left(\sum_{t=1}^{T} D_{i t k} x_{i t}\right) e^{\sum_{t=1}^{T} D_{i t k} x_{i t} \beta}\right)}{\left(\sum_{S}\left(\sum_{t=1}^{T} D_{i t k}\right) e^{\sum_{t=1}^{T} D_{i t k} x_{i t} \beta}\right)^{2}} \\
-\frac{\left[\sum_{S\left(\sum_{t=1}^{T} D_{i t k}\right)}\left(\sum_{t=1}^{T} D_{i t k} x_{i t}\right)\left(\sum_{t=1}^{T} D_{i t k} x_{i t}\right) e^{\sum_{t=1}^{T} D_{i t k} x_{i t} \beta}\right] \sum_{S\left(\sum_{t=1}^{T} D_{i t k}\right)} e^{\sum_{t=1}^{T} D_{i t k} x_{i t} \beta}}{\left(\sum_{S\left(\sum_{t=1}^{T} D_{i t k}\right)} e^{\sum_{t=1}^{T} D_{i t k} x_{i t} \beta}\right)^{2}} \\
=A * A-\frac{\sum_{S\left(\sum_{t=1}^{T} D_{i t k}\right)}\left(\sum_{t=1}^{T} D_{i t k} x_{i t}\right)\left(\sum_{t=1}^{T} D_{i t k} x_{i t}\right) e^{\sum_{t=1}^{T} D_{i t k} x_{i t} \beta}}{\sum_{S\left(\sum_{t=1}^{T} D_{i t k}\right)} e^{\sum_{t=1}^{T} D_{i t k} x_{i t} \beta}} \\
\text { With } A=\frac{\sum_{S\left(\sum_{t=1}^{T} D_{i t k}\right)}\left(\sum_{t=1}^{T} D_{i t k} x_{i t}\right) e^{\sum_{t=1}^{T} D_{i t k} x_{i t} \beta}}{\sum_{S\left(\sum_{t=1}^{T} D_{i t k}\right)} e^{\sum_{t=1}^{T} D_{i t k} x_{i t} \beta}} \operatorname{corresponding~to~the~second~term~of~}
\end{gathered}
$$
the gradient function. 


\title{
2 Offshoring and Job Loss Fears: An Economet- ric Analysis of Individual Perceptions
}

Authors: Ingo Geishecker, Maximilian Riedl and Paul Frijters

Published in Labour Economics, 2012, Volume 19, Number 5, p. 738-747.

Online available http://dx.doi.org/10.1016/j.labeco.2012.05.018

\begin{abstract}
We quantify the impact of offshoring and other globalisation measures on individual perceptions of job security. For the analysis we combine industry-level offshoring measures with micro-level data from a large German household panel survey and estimate ordinal fixed effects models. Our results indicate that offshoring to low-wage countries significantly raises job loss fears whilst offshoring to high-wage countries somewhat lowers them. Over our sample period from 1995 to 2006, offshoring to low and high-wage countries together can account for about $13 \%$ of the total increase in job loss fears. High-skilled workers are more sensitive to offshoring although their objective job loss risk is lower relative to low-skilled workers, which we argue reflects the fact that they have more to lose from unemployment.
\end{abstract}




\section{Offshoring, Job Loss Fears and Wage Bargain- ing 1}

Author: Maximilian Riedl

\subsection{Introduction}

It is a common phenomenon that during wage negotiations firms use the threat of shifting domestic jobs abroad in order to lower the result of the wage bargaining. ${ }^{2}$ If wages are the result of collective bargaining between firms and trade unions, it is often argued that offshoring strengthens the bargaining power of firms, which results in lower wages (see, e.g. Eckel and Egger, 2009). In this paper I argue that workers perceive job loss fears which lowers their individual utility. Offshoring affects these fears and workers are willing to accept a lower outcome during wage negotiations. Specifically, it is the threat of potential offshoring which increases fear, and not necessarily actual offshoring.

In their recent article Geishecker et al. (2012) find that international outsourcing or offshoring towards low-wage countries increases job loss fears of German workers. These fears could have effects on wages when they are determined by negotiations between firms and workers individually or collectively. For example, Manski (2004) mentions the importance of the perception of job insecurity as a determinant for wages and employment. These concerns are mostly reasonable and justified and are indicative of real future job loss. Clark (2001), Stephens, Jr. (2004) and Dickerson and Green (2012) show that individual perceptions of job loss probabilities can be robust and valid predictors for actual job loss probabilities.

In the previous literature regarding the impact of offshoring on wages, these perceptions are not considered. So far, a lot of research has been done regarding the effect

\footnotetext{
${ }^{1}$ This chapter was published in an earlier version as: "Wage Bargaining, Job Loss Fears and Offshoring", CEGE Discussion Papers No. 174, 2013.

${ }^{2}$ There is much evidence regarding those threats during wage negotiations reported in the media, e.g., in March 2013 during wage negotiations of the German trade union IG Metall and the employers' association: http://www.focus.de/finanzen/news/wirtschaftsticker/roundup-tarifverhandlungenfuer-740-000-metall-beschaeftigte-vertagt_aid_945640.html.
} 
of offshoring on wages, both theoretically and empirically. It is known that mostly high-skilled workers benefit from offshoring, whereas low-skilled workers usually have to accept lower wages. Recent literature, however, changed the perspective from a skill to a task oriented view of wage effects from offshoring. Workers who perform tasks which are more interactive and non-routine are more protected from offshoring, irrespective of the skill level. Nevertheless, this is the first study to incorporate individual perceptions like job loss fears into the effect of offshoring on wages.

I extend the model of Skaksen (2004), where wages are determined via wage bargaining between firms and trade unions and introduce individual perceived fear of job loss as an additional term into the worker's utility function. Firms have the possibility to chose between in-house production or purchasing intermediate goods, used in the production process, from abroad. During wage negotiations, firms can use the possibility to offshore as a threat to increase worker's job loss fears. I use a Nash wage bargaining model with a right-to-manage setting and find that with increasing job loss fears, workers are willing to accept lower wages.

In the empirical application I test these theoretical implications, namely whether a general increase of job loss fears lowers wages and whether increasing potential offshoring lowers wages through different levels of job loss fears. In order to show this, I use large German household panel data combined with industry level offshoring measures. Since I argue that potential but not realised offshoring affects the wage bargaining outcome, world-wide export supply of intermediate goods is used to approximate potential offshoring. The empirical results confirm the theoretical implications.

This paper is structured in the following way. In the next section I briefly discuss the existing literature on offshoring and wages, wage bargaining and perceived job insecurity. In Section 3.3 I present a right-to-manage wage bargaining model and show how individual job loss fears impacts the Nash bargaining solution. The empirical analysis is carried out in Section 3.4. I describe the data used and explain the empirical model. After that I interpret the estimation results. Section 3.5 concludes. 


\section{$3.2 \quad$ Literature}

When looking at the theoretical literature, the impact of offshoring on wages is not clear cut ${ }^{3}$ In previous studies authors like Feenstra and Hanson (1996a), Arndt (1997, 1999) and Kohler (2004) apply general equilibrium models with competitive labour markets and come to different conclusions. Depending on the assumptions and framework of their models, relative wages of low- to high-skilled workers may rise or fall.

A large body of literature models the effect of offshoring on wages where wages are determined on imperfect labour markets via collective bargaining. In Skaksen (2004) wages are negotiated between firms and trade unions in a right-to-manage model. After wage bargaining the firm can decide whether to outsource one activity of its production process or not. The author finds that the threat of potential outsourcing lowers wages, whereas actual outsourcing results in higher wages. Ranjan (2013) comes to similar results. He applies a Pissarides search model to look at unemployment and finds that decreasing offshoring costs lowers unemployment first but increases unemployment when offshoring costs are sufficiently low. Gaston (2002) uses an efficient wage bargaining model where both wages and employment are negotiated and firms use offshoring as a threat to lower wages. His model also predicts higher wages and lower employment if offshoring takes place. However, contrary findings are in Koskela and Stenbacka (2009) where the firm decides to offshore before wage negotiations. They find that increasing offshoring rises the wage elasticity of labour demand which results in lower wages and unemployment. Additionally, Eckel and Egger (2009), Egger and Kreickemeier (2009) and König and Koskela (2011) also focus on the bargaining power of trade unions and find that the effect of offshoring on wages can be positive or negative, depending on the power of the unions. However, the better fall back option for firms to shift production to foreign countries lowers the bargaining power of unions and therefore also the wages of the union members.

Although all articles mentioned above name the threat of potential offshoring as a form of pressure during wage negotiations, none of the models take that explicitly into account. In this paper, the effect of this threat is considered in more detail. Trade

\footnotetext{
${ }^{3}$ For an extensive view over the previous literature on the effects of offshoring on wages, both theoretically and empirically, see, e.g. Harrison et al. (2011).
} 
union members experience direct utility losses in the form of job loss fears through the threat of potential offshoring. This way I can show that by increasing fears the Nash solution of the collective bargaining results in lower wages. Therefore I claim that job loss fears are an additional channel to explain labour market effects of offshoring.

The existing empirical literature mainly examines the impact of actual offshoring on wages for different skill groups or different tasks. Studies of, e.g., Geishecker and Görg (2008), Geishecker, Görg and Munch (2010) and Hummels, Jørgensen, Munch and Xiang (2011) find a negative wage effect for low-skilled workers and a positive effect for high-skilled workers, indicating that mostly low-skilled labour is threatened by offshoring. Initiated by the theoretical work of Grossman and Rossi-Hansberg (2008), there is a growing amount of literature that examines the impact of offshoring on the wages of workers performing different tasks. Baumgarten et al. (2013) and Ebenstein et al. (forthcoming) find that the focus on offshoring tasks is more important than that on skill levels. Their results show distinctive negative wage effects for workers performing routine and non-interactive tasks, irrespective of the skill level. In addition to skill and task related effects on wages, this paper emphasizes the role of individual perceptions, in this case job loss fears, in connection with the effect of the threat of potential offshoring on wages.

As mentioned above, the existing theoretical literature often explains the wage reducing effect of offshoring as a consequence of lower bargaining power of trade unions. In Brock and Dobbelaere (2006), Dumont, Rayp and Willemé (2006) and Dumont, Rayp and Willemé (2012) the authors empirically assess the effect of international trade on the bargaining power of trade unions. While Dumont et al. (2006) and Dumont et al. (2012) find a negative influence of internationalization on the bargaining power of unions, Brock and Dobbelaere (2006) only find small and no significant effects for the Belgian manufacturing industry

Of the papers that investigate the effect of individual perceptions like job loss fears on wages, Blanchflower (1991) studies the effect of fear of unemployment on wages of British workers in the 1980s. He argues that when the wage rate is the result of

\footnotetext{
${ }^{4}$ Dreher and Gaston (2007) also empirically assess the bargaining power of 17 OECD countries. They use union membership as a measure for bargaining power and find no direct link between globalization and bargaining power.
} 
bargaining between firms and trade unions, wages are lower if workers have to fear unemployment. His empirical results show that if workers expect redundancy or plant closure within the next year, wages are around 8 percent lower. Campbell, Carruth, Dickerson and Green (2007) find that past unemployment and unemployment of near family members and friends are linked with higher fears of unemployment. They also find that higher fears of unemployment lead to lower wage growth for men.

Goerke and Pannenberg (2012) state that individual perceptions and attitudes play an important role in wage negotiations. They theoretically and empirically look at risk aversion and collective bargaining for Germany and find that increasing risk aversion leads to lower wages.

Investigating how FDI and offshoring affect individual job loss fears, Scheve and Slaughter (2004) use industry FDI and Geishecker et al. (2012) take industry FDI and offshoring measures and link them with individual data on perceived job security. Scheve and Slaughter (2004) find that increasing FDI leads to increasing job insecurity of British workers. FDI increases the elasticity of labour demand and thus wage and employment volatility. Consequently, individual job insecurity rises. Related to the effects of FDI, Geishecker et al. (2012) find that offshoring toward low-wage countries increases individual job loss fears of German workers.

Besides the importance of subjective measures in collective bargaining, the perception of job security is also an important determinant for individual well-being and overall utility (see, e.g. Frey and Stutzer, 2002). Thus, the aim of this paper is to theoretically and empirically assess the effect of job loss fears on wages in the presence of collective bargaining, when firms have the possibility to offshore parts of their production abroad.

\subsection{Wage bargaining with job loss fears}

The model presented in this paper builds on a general equilibrium model, where wages are determined by Nash wage bargaining with optional offshoring. In a right-to-manage setting the trade union is first negotiating with the firms over wages. In a second step firms can decide over the amount of labour demand and have the possibility to offshore parts of their production to maximize their profits. 
A very similar framework can be found in Skaksen (2004). This paper, however, differs in two aspects. First, firms can use the possibility to shift production abroad as a threat in order to enforce lower domestic wages. I introduce the fear of job loss as a channel through which this threat is affecting worker's utility. Thus, job loss fears are modelled as an additional component in the utility function of the union members. Second, union members are heterogeneous in their individual perception of job loss fears and it is the median member of the trade union who determines the wage bargaining outcome $5^{5}$ As a consequence, the Nash wage bargaining solution shows, that with an increasing threat of potential offshoring, and therefore higher job loss fears, the trade union accepts lower wages.

\subsubsection{Firms}

The representative firm is producing one homogeneous good according to a CobbDouglas production function with decreasing returns to scale:

$$
Q=N^{\alpha} H^{\beta}, \quad \alpha+\beta<1,
$$

where $Q$ is the quantity of the produced good, $N$ is the labour input for the in house activity which cannot be offshored and $H$ is the intermediate input which can either be produced in house or be purchased abroad (offshoring). Depending on whether the firm does offshoring or not, labour demand can be either $L=H$ or $L=N+H$. In order to prevent workers to switch between the two production factors, wages have to be equal for both factors.

According to the right-to-manage model, after the wage of in-house production is negotiated, the firm sets the amount of in-house labour demand and can decide whether to offshore the production of the intermediate good or not. Offshoring takes place if the cost of in-house labour exceeds the cost of offshoring. The firm's decision is based on maximizing the following profit function:

$$
\Pi=Q-w L-c Z,
$$

\footnotetext{
${ }^{5}$ For an extensive description of right-to-manage and the median voter model, see, e.g. Booth (1994).
} 
where the price of the produced good is set to one, $w$ is the wage rate for in house labour $L, c$ is the cost for offshoring including trade costs and $Z$ is the quantity of the intermediate input in case of offshoring.

\subsubsection{Labour market}

All domestic workers are organized in one trade union and are collectively negotiating about the wage rate through Nash wage bargaining. In these wage bargaining solutions wages are usually higher than in a competitive labour market and labour demand is lower than the total endowment of union members, i.e. each member is faced with a probability of not getting employed. Beside this objective probability of job loss, I now introduce subjective individual job loss fears in the worker's utility function.

According to authors like Schmidt (1999), Green, Felstead and Burchell (2000), Manski and Straub (2000) and Nickell et al. (2002) job loss fear is decomposed into two components: the perceived probability of job loss and the subjective cost of job loss. Here, the subjective probability of job loss is a consequence of the uncertainty about the exact costs of offshoring. Workers observe offshoring activities in their domestic markets or outside their own country, while firms put pressure onto their workers during wage negotiations with the possibility to offshore parts of the production abroad. Workers sense this threat of potential offshoring and develop an own individual and subjective probability of getting displaced. This subjective probability is multiplied with the cost of job loss, which can be both actual monetary losses and non-pecuniary utility losses (see, e.g. Green et al., 2000). As a result, this gives the expected subjective loss of utility in case of unemployment. Hence, the utility of each employed worker $i$ is a function of the utility of the wage $w$ minus the job loss fear components $p_{i} \times[U(w)-U(\bar{w})]$ :

$$
U_{i}^{w}=U(w)-p_{i}[U(w)-U(\bar{w})]
$$

with the subjective individual probability of job loss $p_{i}$ and $\bar{w}$ as the reservation wage. The probability $p_{i}$ has the functional form of a Pareto distribution:

$$
p_{i}(w, k)=1-\left(\frac{\bar{w}}{w}\right)^{k},
$$


where $w>\bar{w}$ and $k>0$. Workers differ in their perception of job loss fears, or more precisely, in their perceived probability of job loss, which is a function of the wage $w$ and a perception parameter $k$. This parameter $k$ is generally increasing with lower offshoring costs, i.e. $\partial k / \partial c<0$. As already mentioned above, workers do not know the exact amount of offshoring costs. Instead, they perceive the threat of potential offshoring through their environment, such that decreasing offshoring costs intensify this threat, which in turn results in higher $k$. Inserting $U(w)=w, U(\bar{w})=\bar{w}$ and $p_{i}$ from Equation 3.4 the utility function of Equation 3.3 becomes:

$$
U_{i}^{w}=\bar{w}+\bar{w}^{k} w^{1-k}-\bar{w}^{k+1} w^{-k}
$$

and the first and second derivative with respect to $w$ are

$$
\begin{array}{r}
\frac{\partial U_{i}^{w}}{\partial w}=(1-k) \bar{w}^{k} w^{-k}+k \bar{w}^{k+1} w^{-k-1} \\
\frac{\partial^{2} U_{i}^{w}}{\partial w^{2}}=-k(1-k) \bar{w}^{k} w^{-k-1}-k(1+k) \bar{w}^{k+1} w^{-k-2} .
\end{array}
$$

Figure 3.1 shows the graph of the utility function for $k=0, k=1$ and $k=2$, representing three different threat scenarios for one worker. From this graph it can be seen that the utility function has different properties regarding the value of the individual perception parameter $k$ :

- $\mathbf{k}=\mathbf{0}:$ In the absence of job loss fears the utility function is constantly increasing in $w: U_{i}^{\prime}(w)>0$ and $U_{i}^{\prime \prime}(w)=0$.

- $\mathbf{0}<\mathbf{k} \leq \mathbf{1}$ : The utility function is increasing in $w$ with a decreasing marginal utility: $U_{i}^{\prime}(w)>0$ and $U_{i}^{\prime \prime}(w)<0$.

- $\mathbf{k}>\mathbf{1}$ : The utility function is initially increasing in $w$ with a decreasing marginal utility until the function reaches its maximum value at $w=\frac{k \bar{w}}{k-1}$. After $w=\frac{(1+k) \bar{w}}{k-1}$ the second derivative is changing its sign from being negative to positive.

In this bargaining environment, where all union members are heterogeneous regarding the perception parameter $k$, it is the median member of the trade union who decides if the bargained wage rate is accepted or not. Accordingly, it is the individual 


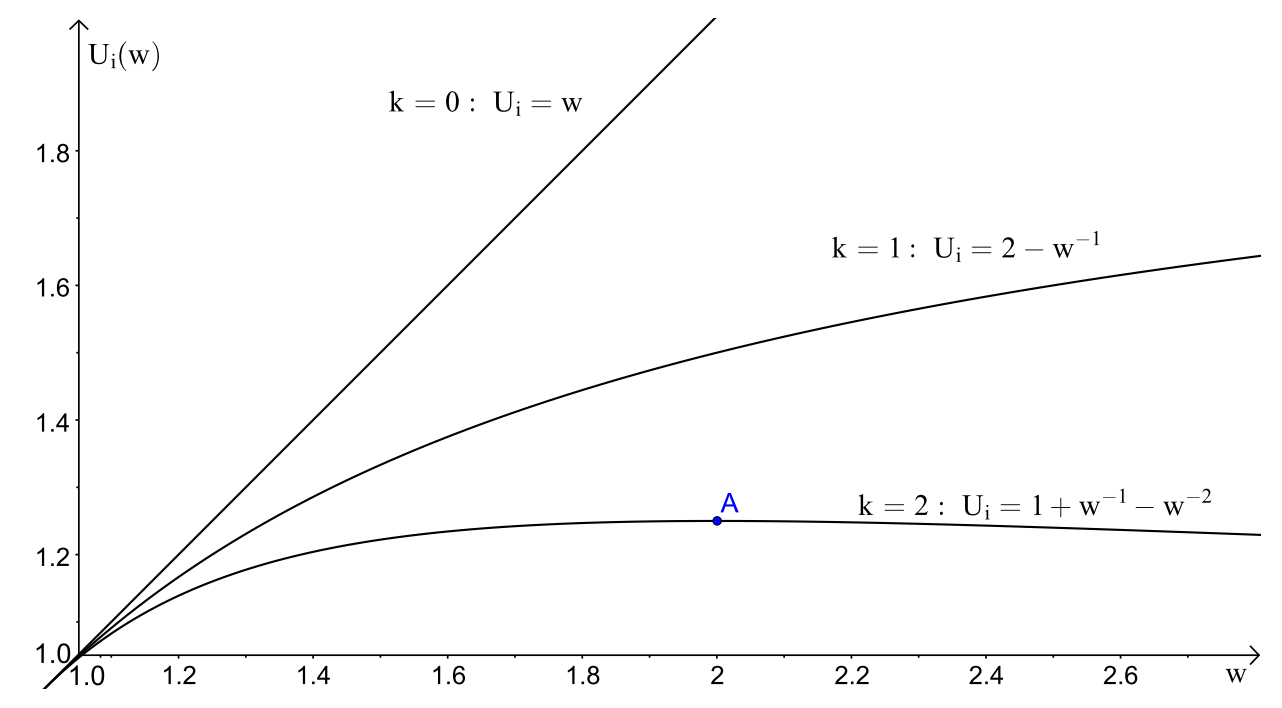

Figure 3.1: Utility function for different k. A: maximum utility for $k=2$.

parameter $k$ of the median member of the union which is crucial for determining the Nash bargaining solution.

In case of a successful negotiation, the expected outcome of the median member is the following:

$$
U_{m}=\frac{L}{M} U_{m}^{w}+\left(1-\frac{L}{M}\right) U_{m}^{\bar{w}}
$$

where the subscript $m$ stands for the median member and $U_{m}^{w}$ is the utility of the employed median member derived from Equation $3.3, L / M$ is the actual probability of getting employed after the wage is set. It is the fraction of labour demand $L$ over the total number of union members, $M . U_{m}^{\bar{w}}$ is the utility of the median member in case of unemployment and is set to $U_{m}^{\bar{w}}=\bar{w}$.

To get the Nash wage bargaining solution, the Nash product NP has to be maximized with subject to the wage rate $w$, see e.g. Binmore, Rubinstein and Wolinsky (1986):

$$
\max _{w}: N P=\left(U_{m}-U_{m}^{\bar{w}}\right)^{\gamma}(\Pi-\bar{\Pi})^{1-\gamma}
$$

where $U_{m}$ is derived from Equation 3.8 and $U_{m}^{\bar{w}}=\bar{w}$ is the utility of the median worker in case of a conflict. $\Pi$ is derived from Equation 3.2 and the profit for the firm in case 
of a conflict is $\bar{\Pi}=0$. In case of a conflict, all workers are unemployed. The bargaining power of the trade union and the firm is represented by the exponent $\gamma$ and $1-\gamma$, respectively.

\subsubsection{Nash wage bargaining}

The right-to-manage model consists of two stages. In the first stage the wage is negotiated between the trade union and the firms and in the second stage the firms determine employment and offshoring, taking into account the negotiated wage from the first stage. To solve this sequential game backwards, I first derive the demand of in house labour, given the wage rate $w$ and offshoring $\operatorname{costs} c$. Unlike the union members, firms do have exact information about the costs of offshoring. After that, the optimal wage bargaining solution is obtained by maximizing the Nash product with subject to $w$, knowing the profit maximizing labour demand of the firms.

\subsubsection{Stage 2}

To get the optimal domestic labour demand, the profit function of the firm from Equation 3.2 is maximized with subject to $L$. In-house employment differs if the firm does offshoring or not:

$$
L= \begin{cases}N+H=\left(A_{1}+A_{2}\right) w^{\frac{-1}{1-\alpha-\beta}}, & \text { if } w \leq c \\ N=A_{1} w^{\frac{\beta-1}{1-\alpha-\beta}} c^{\frac{-\beta}{1-\alpha-\beta}}, & \text { if } w>c,\end{cases}
$$

where $A_{1}=\alpha^{\frac{1-\beta}{1-\alpha-\beta}} \beta^{\frac{\beta}{1-\alpha-\beta}}$, and $A_{2}=\alpha^{\frac{\alpha}{1-\alpha-\beta}} \beta^{\frac{1-\alpha}{1-\alpha-\beta}}$. In the first case wages are below offshoring costs and the firm produces the intermediate input at home $(L=N+H)$. Unsurprisingly, labour demand is decreasing in $w$. In the second case wages are higher than offshoring costs and the firm employs domestic workers only in the first activity $(L=N)$. Labour demand is decreasing in $w$ and $c$.

Accordingly, the profit maximizing demand for purchasing the intermediate input 
abroad is:

$$
Z= \begin{cases}0, & \text { if } w \leq c \\ H=A_{2} w^{\frac{-\alpha}{1-\alpha-\beta}} c^{\frac{\alpha-1}{1-\alpha-\beta}}, & \text { if } w>c .\end{cases}
$$

If the cost of offshoring is above domestic wages the firm does not offshore and the demand of the abroad produced intermediate input is zero. In the second case the firm does offshoring due to lower offshoring costs and demand $Z$ is positive and decreasing in $w$ and $c$.

\subsubsection{Stage 1}

In the first stage the wage is negotiated between the firm and the trade union, both taking the level of employment from the second stage into account. The Nash bargaining solution is obtained by the wage $\hat{w}$, which maximizes the Nash product from Equation 3.9. As already mentioned above, the fear of job loss is depending on the individual perception parameter $k$, which is increasing with the threat of potential offshoring when offshoring costs are decreasing. Trade union members have no full information on $c$. They can only perceive the threat of potential offshoring and can make predictions of $c$ via offshoring activities in other countries or industries.

The first order condition for maximizing the Nash product from Equation 3.9 with subject to $w$ is:

$$
\frac{\partial N P}{\partial w}=\gamma \frac{\partial U_{m}(w) / \partial w}{U_{m}(w)-U(\bar{w})}-\gamma \frac{\partial L(w) / \partial w}{L(w)}+(1-\gamma) \frac{\partial \pi(w) / \partial w}{\pi(w)}=0
$$

Inserting the profit function of the firm $\pi$ from Equation 3.2 and labour demand $L(w)$ from Equation 3.10, the first order condition becomes:

$$
\frac{\partial N P}{\partial w}=\gamma \frac{1-k+k \bar{w} w_{-1}}{w-\bar{w}}+\frac{(1-\gamma)(-\alpha-\beta)-\gamma}{(1-\alpha-\beta) w}=0
$$

Solving Equation 3.13 for $\hat{w}$ yields:

$$
\hat{w}=\bar{w}\left(1+\frac{\gamma(1-\alpha-\beta)}{\alpha+\beta+k \gamma(1-\alpha-\beta)}\right) .
$$


The wage $\hat{w}$ of the Nash bargaining solution is a function of the reservation wage $\bar{w}$, the parameters $\alpha$ and $\beta$ from the production function, the bargaining power of the trade union $\gamma$, and the median member's perception parameter $k$. The firm threatens the union members with the possibility of offshoring, and as a result, the fear of losing employment lowers the optimal wage rate through the parameter $k$. The higher the median union member perceives the threat of potential offshoring, the lower the Nash bargaining solution:

$$
\frac{\partial \hat{w}}{\partial k}=-\bar{w} \gamma^{2} \frac{(\alpha+\beta-1)^{2}}{[\alpha+\beta+k \gamma(1-\alpha-\beta)]^{2}}<0 .
$$

However, there are two solutions from maximizing the Nash product, differentiated by the median member's perception of the threat of potential offshoring:

$$
\hat{w}= \begin{cases}\hat{w}_{1}=\bar{w}\left(1+\frac{\gamma(1-\alpha-\beta)}{\alpha+\beta+k \gamma(1-\alpha-\beta)}\right), & \text { if } k \leq z \\ \hat{w}_{2}=\bar{w}\left(1+\frac{\gamma(1-\alpha-\beta)}{\alpha}\right), & \text { if } k>z .\end{cases}
$$

In the first scenario, union members are concerned about their future employment and are willing to accept lower wages in order to prevent the firm from offshoring and to keep employment for both production factors in house. The willingness of the trade union members to agree to a wage cut is, however, limited. In a second scenario the threat of potential offshoring is so strong, i.e. $k$ is greater than the threshold variable $z$, that the trade union accepts offshoring and only negotiates over the wage for employment in the first factor, which cannot be offshored. In this case, the expected utility of the median member must be higher than in the first scenario. However, since offshoring is happening now, domestic employment is lower (see Equation 3.10.

As already mentioned above, Skaksen (2004) uses a similar framework regarding the firms' decision for offshoring and the determination of wages via Nash bargaining. He describes three different outcomes for the Nash wage bargaining, depending on the costs of offshoring. In one scenario offshoring costs are so high that the firm will never do offshoring and the wage bargaining solution is as if offshoring is not possible. In the other scenario offshoring costs are so low that union members accept offshoring and negotiate only over the wage for the remaining in-house production. However, in 
the most interesting scenario the bargaining outcome has no analytical result. Skaksen argues that there exists an interval in which the costs of offshoring are sufficiently low to threaten domestic employment while high enough so that the workers are willing to accept wage cuts to prevent the firm from offshoring. As the only possible solution Skaksen proposes the wage that is exactly equal to the costs of offshoring so that the firm just decides to produce at home. In the model described above it is now possible to find an analytical result for this scenario because there exists a $k$ which reproduces the result of Skaksen (2004). To show this, the Nash bargaining solution from Equation 3.14 has to be equal to the cost of offshoring:

$$
\bar{w}\left(1+\frac{\gamma(1-\alpha-\beta)}{\alpha+\beta+k \gamma(1-\alpha-\beta)}\right)=c
$$

Solving this equation for the fear perception parameter $k$, gives:

$$
k=\frac{1}{\gamma}\left(\frac{\alpha+\beta}{\alpha+\beta-1}+\frac{\gamma}{\frac{c}{w}-1}\right)
$$

Thus, if the fear perception parameter $k$ of the median trade union member equals exactly Equation 3.18, $\hat{w}=c$ is a Nash bargaining solution in the presence of job loss fears. Accordingly, the solution of Skaksen (2004) is a special case of the Nash bargaining model presented in this paper. The Nash bargaining result of Equation 3.14 is in fact much more general and allows wage rates which are even below the costs of offshoring, depending how strong the fear of job loss is.

\subsection{Empirical analysis}

A large part of the German wages are negotiated industry-wide between employers and trade unions. This wage applies, however, often only as a base trade. In addition to this industry-wide wage floor, many non-tariff payments are individually negotiated between the company and its employees, and hence leads to different individual wages.

One advantage of the the median voter concept in the collective bargaining model is that the same results can be drawn for individual wage bargaining. In the collective wage bargaining model, it is the utility function of the median voter which is crucial for the wage of all union members. To change the setting to an individual wage bargaining 
model, the utility function of the median member has to be replace with the utility function and fear level of the respective individual. The result of decreasing wages with increasing fears will still be the same.

In this section two implications of the theoretical model are empirically evaluated with combined micro and industry data for the German manufacturing sector. The first implication to check is, whether increasing job loss fear results in lower wages. The second, whether the threat of potential offshoring lower wages through different levels of job loss fear.

\subsubsection{Data}

For this analysis I use micro data at the individual level from the German SocioEconomic Panel (SOEP), a large longitudinal survey of private households, for the years 1995 to 2008.6 The focus is on male and female full-time workers of the manufacturing sector (NACE 15-36) at the age of 18 to 65 years. The dependent variable is the natural logarithm of real hourly wages, constructed from the Cross-National Equivalent File $(\mathrm{CNEF})$ of the SOEP. Hourly wages are yearly total wages and salaries from main job (reported the previous year) with 13th and 14th month salary, profit sharing and vacation and Christmas bonus, divided by the total amount of working hours per year.

The variable measuring perceived job loss fear is yearly obtained from the SOEP by asking the respondents how concerned they are about their job security. The respondents can answer in three categories: not concerned at all; somewhat concerned; very concerned. Accordingly, the variable is coded in ordinal scale of three categories.

In the theoretical model it is potential and not realised offshoring that is threatening the workers' jobs. However, potential offshoring cannot be observed and is therefore approximated by world-wide export supply of intermediate goods. World-wide export supply has been used only for instrumenting actual offshoring in the empirical literature like e.g., in Baumgarten et al. (2013), and is now used as a proxy for potential offshoring for the first time. It is measured at the 2 digit industry level and is obtained from the

\footnotetext{
${ }^{6}$ For more details on the German SOEP, see e.g. Wagner, Frick and Schupp (2007). The data used in this paper was extracted using the Add-On package PanelWhiz for Stata. PanelWhiz (http://www.PanelWhiz.eu) was written by Dr. John P. Haisken-DeNew (john@PanelWhiz.eu). See Haisken-DeNew and Hahn (2010) for details. The PanelWhiz generated DO file to retrieve the data used here is available from the author upon request. Any data or computational errors in this paper are my own.
} 
UN Comtrade database. To prevent problems of endogeneity, world-wide export supply includes all countries reported except Germany.

As a short robustness check, actual offshoring is also used in this analysis. Actual offshoring is measured as an extended version of the narrow concept of Feenstra and Hanson (1999), which means that it only captures intermediate inputs denoted to the corresponding industry of itself: $]^{7}$ For constructing actual offshoring, import data from Eurostat COMEXT are combined with input-output tables from the German Federal Statistical Office.

To capture additional industry-specific characteristics that might affect wages, industry productions values from the Federal Statistical Office of Germany and industry specific R\&D expenditures from the OECD ANBERD database are also used.

\subsubsection{Empirical model and identification}

The empirical model applied here is a standard wage regression with common individual demographic covariates, like in Mincer (1974), Brown and Medoff (1989), Schmidt and Zimmermann (1991), extended with variables for individual job loss fears, potential offshoring and several other covariates capturing industry specific characteristics:

$$
\begin{aligned}
\ln W_{i j t}= & \alpha+\gamma \mathrm{FEAR}_{i t-1}+\delta \operatorname{lnOFF}_{j t+1}+\eta \mathrm{FEAR}_{i t-1} \times \ln \mathrm{OFF}_{j t+1} \\
& +\beta \mathrm{X}_{i t}+\tau \mathrm{IND}_{j t}+\theta_{t}+\lambda_{j}+\mu_{i}+\epsilon_{i j t}
\end{aligned}
$$

The dependent variable is the log of hourly wages $W$ for individual $i$ in industry $j$ at time $t$. The variable FEAR stands for the level of individually perceived fear of job loss. It is measured in three categories and is recoded into three dummy variables indicating low, medium and high fears. In the theoretical model individual job loss fear is a function of the current wage. Including job loss fear in time $t$ into the empirical model would lead to simultaneity problems. For that reason, FEAR goes into the model with a one period lag, assuming that past fears may explain current wages but current wages cannot influence past individual fears.

OFF is potential offshoring for industry $j$ and is measured as world-wide export supply of intermediate goods excluding Germany. If supply of intermediate goods of

\footnotetext{
${ }^{7}$ For a more detailed description of this offshoring measure, see the appendix of chapter 2 or Geishecker et al. (2012).
} 
the rest of the world increases, it indicates that costs of offshoring decreases so that it is more attractive for domestic firms to purchase intermediate goods from abroad. Domestic workers see future world-wide trade in intermediate goods as an indicator for potential offshoring for their domestic firms and therefore as a threat for their jobs 8 Potential offshoring is split into high- and low-wage countries, where high-wage countries are defined as "advanced economies" from the IMF International Financial Statistics $9^{9}$ The reason behind is that worker may see only export of intermediate goods from low-wage countries as a threat for their jobs.

Additionally, there could also be a simultaneity problem with future world-wide export supply of intermediate goods and wages. This problem can be avoided by using individual wage data and arguing that aggregate industry export supply is unlikely to be determined by individual wages (see, e.g., Ebenstein et al., 2011 and Baumgarten et al., 2013). Furthermore, Germany is excluded as export supplier and partner country in the export supply data. Hence, the most likely occurring case that German wages may determine export activities towards Germany can be excluded.

$\mathrm{X}$ is a vector of individual demographic variables including dummy variables for four different age intervals, dummies for low, medium and high levels of education 10 , and dummy variables for being married and for having children. Furthermore, there are variables on work related individual characteristics like tenure, work experience, occupation and firm size. IND denotes Industry production values and research and development intensities and are accounting for industry specific wage effects. For detailed descriptive statistics on all variables used in this analysis, see Table 3.1 .

In order to control for as much observed and unobserved heterogeneity as possible, the model also controls for time fixed effects $\theta_{t}$, industry fixed effects $\lambda_{j}$ and individual fixed effects $\mu_{i}$. Additionally, regional dummies at the federal state level and industry specific time trends are also included and $\epsilon_{i j t}$ is the residual error term. This model is estimated with OLS with clustered standard errors at the combined industry federal state mode applying the sandwich formula of White (1980) and Arellano (1987).

\footnotetext{
${ }^{8} \mathrm{I}$ assume that on average, workers can make perfect predictions of future world-wide trade in intermediate goods.

${ }^{9}$ high-wage countries are: EU-15, USA, Canada, New Zealand, Australia, Japan, Norway, Switzerland and Iceland.

${ }^{10}$ Accoring to the OECD International Standard Classification of Education (ISCED), workers are split into low, medium and high-skilled.
} 
Table 3.1: Descriptive statistics

\begin{tabular}{|c|c|c|c|}
\hline Variable & Notes & Mean & SD \\
\hline Real hourly wage & in Euro & 16.67 & 8.75 \\
\hline D: JobLossFear: low & $0 / 1$ & 0.33 & 0.47 \\
\hline D: JobLossFear: medium & $0 / 1$ & 0.50 & 0.50 \\
\hline D: JobLossFear: high & $0 / 1$ & 0.18 & 0.38 \\
\hline D: Age: $18-24$ & $0 / 1$ & 0.03 & 0.16 \\
\hline D: Age: $25-39$ & $0 / 1$ & 0.40 & 0.49 \\
\hline D: Age: $40-54$ & $0 / 1$ & 0.46 & 0.50 \\
\hline D: Age: $55-65$ & $0 / 1$ & 0.12 & 0.32 \\
\hline Tenure & in years & 12.68 & 9.58 \\
\hline Work Experience: full-time & in years & 19.30 & 10.12 \\
\hline Work Experience: part-time & in years & 0.55 & 2.09 \\
\hline D: Education: low & $0 / 1$ & 0.15 & 0.35 \\
\hline D: Education: medium & $0 / 1$ & 0.66 & 0.47 \\
\hline D: Education: high & $0 / 1$ & 0.19 & 0.39 \\
\hline D: Occupation: missing & $0 / 1$ & 0.00 & 0.03 \\
\hline D: Occupation: clerk & $0 / 1$ & 0.08 & 0.27 \\
\hline D: Occupation: service & $0 / 1$ & 0.01 & 0.08 \\
\hline D: Occupation: craft & $0 / 1$ & 0.33 & 0.47 \\
\hline D: Occupation: skilled & $0 / 1$ & 0.18 & 0.39 \\
\hline D: Occupation: unskilled & $0 / 1$ & 0.05 & 0.22 \\
\hline D: Married & $0 / 1$ & 0.72 & 0.45 \\
\hline D: Children & $0 / 1$ & 0.46 & 0.50 \\
\hline D: Firm Size $<20$ & $0 / 1$ & 0.14 & 0.35 \\
\hline D: Firm Size 20 - 199 & $0 / 1$ & 0.24 & 0.43 \\
\hline D: Firm Size 200 - 1999 & $0 / 1$ & 0.09 & 0.29 \\
\hline D: Firm Size > 1999 & $0 / 1$ & 0.02 & 0.15 \\
\hline D: Firm Size missing & $0 / 1$ & 0.00 & 0.05 \\
\hline D: Public Firm & $0 / 1$ & 0.01 & 0.09 \\
\hline Industry Producation Value & in Billion Euro & 104.53 & 62.65 \\
\hline actual: $\mathrm{OFF}^{\text {highwage }}$ & in percentage points & 4.94 & 4.41 \\
\hline actual: $\mathrm{OFF}^{\text {lowwage }}$ & in percentage points & 1.79 & 1.77 \\
\hline $\mathrm{OFF}^{\text {highwage }}$ & in Billion US-Dollar & 242.56 & 208.49 \\
\hline OFF $F^{\text {lowwage }}$ & in Billion US-Dollar & 126.05 & 121.99 \\
\hline $\mathrm{R} \& \mathrm{D} / \mathrm{Y}$ & in percentage points & 2.23 & 2.40 \\
\hline Observations & & 16507 & \\
\hline
\end{tabular}

In this empirical analysis I want to test two predictions of the theoretical model. First, whether an increase in job loss fear lowers wages. Second, whether there is an effect of potential offshoring on wages through the different levels of job loss fears. To test the first prediction, two dummy variables indicating medium and high level of fear capture the effect of individuals who change from no fear to medium or high fear. To test the second prediction the empirical model controls for potential industry offshoring and individual job loss fears separately and multiplied together as an interaction term. 
The coefficient of potential offshoring plus the coefficient of the interaction term gives the effect of changes of potential industry offshoring on wages for different levels of job loss fears as elasticity:

$$
\frac{\partial \ln W_{i j t}}{\partial \ln \mathrm{OFF}_{j t+1}}=\delta+\eta \times \mathrm{FEAR}_{j t-1}
$$

\subsubsection{Estimation results}

Table 3.2 shows the results of the fixed effects OLS regressions for different specifications. They all include individual, workplace and industry characteristics, where almost all coefficients have the expected sign. Wages significantly increase by age and tenure, however, probably due to high multicollinearity with age and tenure, years of work experience have no more additional significant effects on wages. As expected, workers with higher education levels receive significant higher wages. Ceteris paribus, workers get around 7.7 or even 15.7 percent higher wages when changing from low to medium or from low- to high-skilled level, respectively. Being married has a small positive impact on wages, whereas having children has no effect at all. Workers employed in bigger firms with more than 2000 employees also receive higher wages of around 4.7 percent. Interestingly, industry specific characteristics like industry production value and $R \& D$ intensity have no significant effect. With industry specific time trends and industry fixed effects, those covariates do not have any more explanatory power.

The first specification reported in the first column of Table 3.2 also shows the effect of medium and high job loss fears on wages. Perceiving no fear of job loss is represented by the reference category. According to the estimation results, changing from low to medium job loss fear does not have any effect on wages. However, workers who change to high job loss fear experience a wage cut by around 1.6 percent on average, ceteris paribus. This change in fear of job loss corresponds to a change of the perception parameter $k$ from the theoretical model, where increasing $k$, ceteris paribus, lowers the optimal Nash wage bargaining solution. This first specification only shows the stand-alone effect of job loss fears on wages. In the following, I also include potential offshoring individually and interacted with job loss fear to capture the effect of potential offshoring through different levels of job loss fears. 
Table 3.2: Fixed effects OLS wage regressions

\begin{tabular}{|c|c|c|c|c|}
\hline & (1) & $(2)$ & $(3)$ & $(4)$ \\
\hline D: Age: $25-39$ & $\begin{array}{c}0.0671 * * * \\
(0.021)\end{array}$ & $\begin{array}{l}0.0672 * * * \\
(0.021)\end{array}$ & $\begin{array}{c}0.0664^{* * *} \\
(0.021)\end{array}$ & $\begin{array}{l}0.0686^{* * *} \\
(0.021)\end{array}$ \\
\hline D: Age: $40-54$ & $\begin{array}{c}0.0529 * * \\
(0.023)\end{array}$ & $\begin{array}{c}0.0530^{* *} \\
(0.023)\end{array}$ & $\begin{array}{c}0.0525^{* *} \\
(0.023)\end{array}$ & $\begin{array}{c}0.0545^{* *} \\
(0.023)\end{array}$ \\
\hline D: Age: $55-65$ & $\begin{array}{c}0.0744^{* * *} \\
(0.026)\end{array}$ & $\begin{array}{c}0.0746^{* * *} \\
(0.026)\end{array}$ & $\begin{array}{c}0.0739^{* * *} \\
(0.026)\end{array}$ & $\begin{array}{c}0.0757^{* * *} \\
(0.026)\end{array}$ \\
\hline Tenure & $0.0036^{* *}$ & $0.0036^{* *}$ & $0.0035^{* *}$ & $0.0035^{* *}$ \\
\hline Work Experience: full-time & $\begin{array}{c}-0.0235 \\
(0.019)\end{array}$ & $\begin{array}{c}-0.0234 \\
(0.019)\end{array}$ & $\begin{array}{r}-0.0235 \\
(0.019)\end{array}$ & $\begin{array}{r}-0.0233 \\
(0.019)\end{array}$ \\
\hline Work Experience: full-time ${ }^{2}$ & $\begin{array}{c}-0.0003^{* * *} \\
(0.000)\end{array}$ & $\begin{array}{c}-0.0003^{* * *} \\
(0.000)\end{array}$ & $\begin{array}{c}-0.0003^{* * *} \\
(0.000)\end{array}$ & $\begin{array}{c}-0.0003^{* * * *} \\
(0.000)\end{array}$ \\
\hline Work Experience: part-time & $\begin{array}{c}-0.0254 \\
(0.018)\end{array}$ & $\begin{array}{r}-0.0255 \\
(0.018)\end{array}$ & $\begin{array}{r}-0.0255 \\
(0.018)\end{array}$ & $\begin{array}{r}-0.0255 \\
(0.018)\end{array}$ \\
\hline Work Experience: part-time ${ }^{2}$ & $\begin{array}{l}0.0005 \\
(0.001)\end{array}$ & $\begin{array}{l}0.0004 \\
(0.001)\end{array}$ & $\begin{array}{l}0.0005 \\
(0.001)\end{array}$ & $\begin{array}{l}0.0004 \\
(0.001)\end{array}$ \\
\hline D: Education: medium & $\begin{array}{c}0.0742 * * * \\
(0.017)\end{array}$ & $\begin{array}{c}0.0744^{* * *} \\
(0.017)\end{array}$ & $\begin{array}{c}0.0742^{* * *} \\
(0.017)\end{array}$ & $\begin{array}{c}0.0740 * * * \\
(0.017)\end{array}$ \\
\hline D: Education: high & $\begin{array}{c}0.1463^{* * *} \\
(0.049)\end{array}$ & $\begin{array}{c}0.1475 * * * \\
(0.049)\end{array}$ & $\begin{array}{c}0.1473^{* * * *} \\
(0.049)\end{array}$ & $\begin{array}{c}0.1475^{* * *} \\
(0.049)\end{array}$ \\
\hline D: Married & $\begin{array}{c}0.0212^{*} \\
(0.012)\end{array}$ & $\begin{array}{c}0.0210^{*} \\
(0.012)\end{array}$ & $\begin{array}{l}0.0213^{*} \\
(0.012)\end{array}$ & $\begin{array}{l}0.0207^{*} \\
(0.012)\end{array}$ \\
\hline D: Children & $\begin{array}{r}-0.0017 \\
(0.011)\end{array}$ & $\begin{array}{r}-0.0017 \\
(0.011)\end{array}$ & $\begin{array}{r}-0.0018 \\
(0.011)\end{array}$ & $\begin{array}{r}-0.0022 \\
(0.011)\end{array}$ \\
\hline D: Firm Size 20 - 199 & $\begin{array}{l}0.0032 \\
(0.006)\end{array}$ & $\begin{array}{l}0.0031 \\
(0.006)\end{array}$ & $\begin{array}{l}0.0031 \\
(0.006)\end{array}$ & $\begin{array}{l}0.0029 \\
(0.006)\end{array}$ \\
\hline D: Firm Size 200 - 1999 & $\begin{array}{l}0.0118 \\
(0.009)\end{array}$ & $\begin{array}{l}0.0120 \\
(0.009)\end{array}$ & $\begin{array}{l}0.0120 \\
(0.009)\end{array}$ & $\begin{array}{l}0.0118 \\
(0.009)\end{array}$ \\
\hline D: Firm Size > 1999 & $\begin{array}{c}0.0458^{* * *} * \\
(0.015)\end{array}$ & $\begin{array}{c}0.0465 * * * \\
(0.015)\end{array}$ & $\begin{array}{c}0.0462^{* * * *} \\
(0.015)\end{array}$ & $\begin{array}{c}0.0456 * * * \\
(0.015)\end{array}$ \\
\hline D: Firm Size missing & $\begin{array}{l}0.0138 \\
(0.048)\end{array}$ & $\begin{array}{l}0.0141 \\
(0.048)\end{array}$ & $\begin{array}{l}0.0138 \\
(0.048)\end{array}$ & $\begin{array}{l}0.0139 \\
(0.048)\end{array}$ \\
\hline D: Public Firm & $\begin{array}{l}0.0023 \\
(0.024)\end{array}$ & $\begin{array}{l}0.0027 \\
(0.024)\end{array}$ & $\begin{array}{l}0.0024 \\
(0.024)\end{array}$ & $\begin{array}{l}0.0018 \\
(0.024)\end{array}$ \\
\hline Industry Production Value & $\begin{array}{r}-0.0004 \\
(0.000)\end{array}$ & $\begin{array}{r}-0.0005 \\
(0.000)\end{array}$ & $\begin{array}{r}-0.0005 \\
(0.000)\end{array}$ & $\begin{array}{r}-0.0006 \\
(0.000)\end{array}$ \\
\hline$R \& D / Y$ & $\begin{array}{r}-0.0088 \\
(0.006)\end{array}$ & $\begin{array}{r}-0.0084 \\
(0.006)\end{array}$ & $\begin{array}{l}-.01188^{*} \\
(0.007)\end{array}$ & $\begin{array}{r}-0.0089 \\
(0.006)\end{array}$ \\
\hline D: Fear: medium & 0.0002 & 0.0003 & 0.0003 & $\begin{array}{l}0.0321 \\
(0.022)\end{array}$ \\
\hline D: Fear: high & $\begin{array}{c}-0.0158^{* *} \\
(0.007)\end{array}$ & $\begin{array}{c}-0.0158^{* *} \\
(0.007)\end{array}$ & $\begin{array}{c}-0.0158^{* *} \\
(0.007)\end{array}$ & $\begin{array}{l}0.0342 \\
(0.031)\end{array}$ \\
\hline actual: $\mathrm{OFF}^{\text {highwage }}$ & & & $\begin{array}{c}-0.0035 \\
(0.003)\end{array}$ & \\
\hline actual: $\mathrm{OFF}^{\text {lowwage }}$ & & & $\begin{array}{l}0.0006 \\
(0.006)\end{array}$ & \\
\hline $\operatorname{lnOFF}_{t+1}^{\text {highwage }}$ & & $\begin{array}{c}0.0793^{*} \\
(0.047)\end{array}$ & & $\begin{array}{l}0.0780 \\
(0.048)\end{array}$ \\
\hline $\operatorname{lnOFF} \operatorname{lowwage}_{t+1}^{\text {lowage }}$ & & $\begin{array}{c}-0.0692^{*} \\
(0.040)\end{array}$ & & $\begin{array}{c}-0.0604 \\
(0.041)\end{array}$ \\
\hline Fear $^{\text {high }} \times \operatorname{lnOFF}_{t+1}^{\text {highwage }}$ & & & & $\begin{array}{l}0.0128 \\
(0.013)\end{array}$ \\
\hline Fear $^{\text {med }} \times \operatorname{lnOFF} F_{t+1}^{\text {highwage }}$ & & & & $\begin{array}{l}0.0019 \\
(0.011)\end{array}$ \\
\hline Fear ${ }^{\text {high }} \times \operatorname{lnOFF}{ }_{t+1}^{\text {lowwage }}$ & & & & $\begin{array}{c}-0.0255^{*} \\
(0.014)\end{array}$ \\
\hline Fear ${ }^{\text {med }} \times \operatorname{lnOFF}_{t+1}^{\text {lowwage }}$ & & & & $\begin{array}{r}-0.0093 \\
(0.011)\end{array}$ \\
\hline Constant & $\begin{array}{l}3.2162 * * * \\
(0.259)\end{array}$ & $\begin{array}{l}2.9585^{* * *} \\
(0.251)\end{array}$ & $\begin{array}{l}3.2800^{* * * *} \\
(0.260)\end{array}$ & $\begin{array}{l}2.9729 * * * \\
(0.363)\end{array}$ \\
\hline Observations & 16,507 & 16,507 & 16,507 & 16,507 \\
\hline R-squared & 0.865 & 0.865 & 0.865 & 0.865 \\
\hline Number of individuals & 3,636 & 3,636 & 3,636 & 3,636 \\
\hline
\end{tabular}

Reference category: low job loss fear, age 18-25 low education, firm size $<20$ Standard errors in brackets. ***,**,* significant at $1,5,10 \%$.

The second column of Table 3.2 adds potential offshoring, separated into high- and low-wage exporting countries. The results show that potential offshoring has contrary effects on wages, depending on the wage level of the country which supplies the intermediate goods. Increasing export supply of intermediate goods from high-wage countries does have a positive effect, where an one percent increase leads to 0.08 percent higher 
wages, ceteris paribus. However, a one percent increase of export supply of intermediate goods from low-wage countries, i.e. a one percent increase of potential offshoring for domestic firms, lowers wages of domestic workers by 0.07 percent.

Regarding those findings it is important to note that export supply of intermediate goods from high-wage countries does not necessarily means a threat of potential offshoring for domestic jobs. Rather, this effect is similar to empirically observable employment and wage effects of offshoring to high-wage countries, where wages may rise due to increasing labour demand and/or productivity gains, like, e.g. in Ebenstein et al. (forthcoming) and Sethupathy (2013).

Export supply of intermediate goods from low-wage countries, however, can be seen as a threat for domestic jobs. According to the theoretical model, this threat results in lower wages, where the magnitude depends on the level of individually perceived fear of job loss.

To compare the effect of the threat of potential offshoring with the effect of actual offshoring on wages, column 3 of Table 3.2 shows the otherwise same specification now with actual offshoring. The small and also insignificant estimates indicate no effect of within industry changes of actual offshoring, which confirms the findings of empirical studies of e.g., Ebenstein et al. (forthcoming) or Baumgarten et al. (2013). In contrast, within industry changes of potential offshoring are sufficient enough to show their impact on wages.

To test if an increasing threat of potential offshoring does lower wages differently, regarding the level of perceived fear of job loss, the third specification additionally contains estimates of potential offshoring interacted with dummy variables for medium and high levels of job loss fear. The third column of Table 3.2 shows a significant negative effect of the interaction term of potential offshoring and high level of job loss fears. For workers who are in the highest fear category, increasing potential offshoring does have a stronger negative impact on wages than workers who are in the medium or low fear category.

To quantify the magnitude and statistical significance of potential offshoring on wages, the parameter estimates of potential offshoring and the interaction terms are derived from Equation 3.20 . Table 3.3 shows the marginal effects of potential offshoring 
on wages by fear level, as well as standard errors and the test for statistical significance.

Table 3.3: Marginal effects of potential offshoring by fear level

\begin{tabular}{llll}
\hline & Fear: low & Fear: medium & Fear: high \\
\hline $\operatorname{lnOFF}_{t+1}^{\text {highwage }}$ & $\begin{array}{l}0.0780 \\
(0.048)\end{array}$ & $\begin{array}{l}0.0798^{*} \\
(0.048)\end{array}$ & $\begin{array}{l}0.0907^{*} \\
(0.048)\end{array}$ \\
& & & \\
$\operatorname{lnOFF}_{t+1}^{\text {lowwage }}$ & -0.0604 & $-0.0700^{*}$ & $-0.0858^{* *}$ \\
& $(0.041)$ & $(0.041)$ & $(0.041)$ \\
\hline
\end{tabular}

standard errors in brackets. ***,**,* significant at 1, 5, $10 \%$.

Initially, it is striking that the opposing effects established above of export supply of intermediate goods for low- and high-wage countries gain with increasing fears. Even though the effects are only weakly statistical significant, export supply of high-wage countries raises hourly wages by 0.08 and 0.09 percent for worker with medium and high fear levels, respectively. This result seems to be slightly counterintuitive at first sight. For workers who conceive stronger fears, it would be reasonable to be more reserved in demanding higher wages in order to stay employed. One possible reason for this is that workers with a higher fear level may claim a higher wage premium than workers with less fear when there is no increasing threat of potential offshoring.

The effects reported in Table 3.3 match the predicted results of the theoretical model regarding the wage effect of potential offshoring for domestic workers with different fear levels. Increasing potential offshoring lowers the wages for all fear levels differently. For workers with low fears, a one percent increase of potential offshoring lowers hourly wages by 0.06 percent, for workers with medium fears by 0.07 percent and for the workers with high fears the wage loss is strongest with almost 0.09 percent. Only the effect for workers with a high fear level is statistical significant at the 5 percent level, though.

Table 3.4 shows that the percentage changes of the variable for potential offshoring are partly large and volatile. Depending on the industry, the average rate of change for the period 1995 to 2008 is between 0.2 and 15.6 percent. Considering now the sector of motor vehicles (NACE code 34), in which the average yearly change rate is about 13 percent, according to the regression results for the wage of German workers in this industry the following can be stated: 
Table 3.4: Average yearly wage effect of potential offshoring by fear level

\begin{tabular}{rlrrrr} 
NACE & Industry description & yearly average change & \multicolumn{3}{c}{ Effect by fear level } \\
Code & & & & & \\
of potential offshoring & low & med & high \\
\hline & & 7.58 & -0.46 & -0.53 & -0.65 \\
15 & Food products, beverages, tobacco & 2.81 & -0.17 & -0.20 & -0.24 \\
17 & Textiles & 4.66 & -0.28 & -0.33 & -0.40 \\
18 & Wearing apparel; dressing of fur & 0.18 & -0.01 & -0.01 & -0.02 \\
19 & Tanning and dressing of leather & 4.09 & -0.25 & -0.29 & -0.35 \\
20 & Wood and cork, except furniture & 5.98 & -0.36 & -0.42 & -0.51 \\
21 & Pulp, paper and paper products & 15.59 & -0.94 & -1.09 & -1.34 \\
22 & Publishing, printing & 14.28 & -0.86 & -1.00 & -1.22 \\
23 & Coke, refined petroleum products & 8.90 & -0.54 & -0.62 & -0.76 \\
24 & Chemicals and chemical products & 10.57 & -0.64 & -0.74 & -0.91 \\
25 & Rubber and plastic products & 10.06 & -0.61 & -0.70 & -0.86 \\
26 & Other mineral products & 9.77 & -0.59 & -0.68 & -0.84 \\
27 & Basic metals & 11.88 & -0.72 & -0.83 & -1.02 \\
28 & Fabricated metal products & 13.08 & -0.79 & -0.92 & -1.12 \\
29 & Machinery and equipment & 6.97 & -0.42 & -0.49 & -0.60 \\
30 & Office machinery \& computers & 10.53 & -0.64 & -0.74 & -0.90 \\
31 & Electrical machinery \& apparatus & 9.14 & -0.55 & -0.64 & -0.78 \\
32 & Radio, TV and communication & 10.30 & -0.62 & -0.72 & -0.88 \\
33 & Medical, precision and optical instr. & 13.24 & -0.80 & -0.93 & -1.14 \\
34 & Motor vehicles and trailers & 11.86 & -0.72 & -0.83 & -1.02 \\
35 & Other transport equipment & 7.11 & -0.43 & -0.50 & -0.61 \\
36 & Furniture & & & &
\end{tabular}

Note: Author's calculation. All numbers in percentage points. Average change of potential offshoring was calculated using the geometric mean.

- Ceteris paribus, the yearly average increase in potential offshoring of 13 percent causes wage cuts of about 1.1 percent $(13.24 \times-0.0858 \approx-1.14)$ for workers with a high level of fear. Whereas workers with medium or low fears are less affected with a 0.93 and 0.8 percent wage cut, respectively.

- The biggest increase of potential offshoring in the motor vehicles sector was in 2004. Ceteris paribus, this increase affected a cut in wages of workers with strong fears of almost 2.9 percent. For workers with little or no fears wages decreases by 2.3 and 2.0 percent, respectively.

- A worker who was employed in the motor vehicles sector for the entire period capturing this analysis and constantly perceived a high level of job loss fear had to accept a wage cut of 16 percent due to changes of potential offshoring from 1995 to 2008 . Whereas a worker with constantly no fear of job loss but otherwise completely identical, only had to face a wage cut of 11.2 percent, ceteris paribus. 


\subsection{Conclusion}

In this paper I theoretically and empirically show that the increasing opportunities for firms to offshore results in lower wages if workers fear for their jobs.

In the theoretical model firms can chose either to produce the intermediate good in house or purchase it from abroad. Workers are organized in one trade union and differ in their individual perception regarding their job security. Therefore, I introduce job loss fear as an additional term of the worker's utility function. Firms and the trade union are negotiating over wages via Nash wage bargaining. Firms can use the opportunity of relocating parts of the production abroad as a threat to induce workers' fears. The Nash wage bargaining solution shows that rising fears, induced by potential offshoring, leads to lower wages.

For the empirical analysis I use a large German household panel dataset combined with industry-level data. Since it is potential and not realised offshoring which is threatening workers' jobs, world-wide export supply of intermediate goods is used as a proxy for measuring potential offshoring. I find that in general increasing fears of job loss leads to lower wages. Workers who become more anxious, and therefore switch from low to a high level of fear, are paid with 1.6 percent lower wages on average. Moreover, increasing potential offshoring to low-wage countries has a negative impact on wages, where workers with different levels of job loss fear are also affected differently. For instance, in the sector of motor vehicles the cumulative change of potential offshoring from 1995 to 2008 led to declining wages of about 11.2 and 16 percent for workers perceiving a low and a high level of job loss fears, respectively. 


\section{References}

Arellano, Manuel, "Computing Robust Standard Errors for Within-Group Estimators," Oxford Bulletin of Economics and Statistics, 1987, 49, 431-434.

Arndt, Sven W., "Globalization and the open economy," The North American Journal of Economics and Finance, 1997, 8 (1), 71-79.

, "Globalization and Economic Development," The Journal of International Trade E Economic Development, 1999, 8 (3), 309-318.

Baetschmann, Gregori, Kevin E. Staub, and Rainer Winkelmann, "Consistent Estimation of the Fixed Effects Ordered Logit Model," Discussion Paper 5443, IZA 2011.

Baumgarten, Daniel, Ingo Geishecker, and Holger Görg, "Offshoring, tasks, and the skill-wage Pattern," European Economic Review, 2013, 61, 132-152.

Bell, David N.F., Steffen Otterbach, and Alfonso Sousa-Poza, "Work Hours Constraints and Health," IZA Discussion Papers 6126, Institute for the Study of Labor (IZA) November 2011.

Benito, Andrew, "Does job insecurity affect household consumption?," Oxford Economic Papers, 2006, 58 (1), 157-181.

Binmore, Ken, Ariel Rubinstein, and Asher Wolinsky, "The Nash Bargaining Solution in Economic Modelling," RAND Journal of Economics, 1986, 17 (2), 176-188.

Blanchflower, David G., "Fear, Unemployment and Pay Flexibility," Economic Journal, 1991, 101 (406), 483-96.

Böckerman, Petri and Mika Maliranta, "Outsourcing, Occupational Restructuring, and Employee Well-Being: Is There a Silver Lining?," Industrial Relations, 2013, 52 (4), 878-914.

Booth, Alison, The economics of the trade union, Cambridge University Press, 1994.

Brock, Ellen and Sabien Dobbelaere, "Has International Trade Affected Workers Bargaining Power?," Review of World Economics, 2006, 142, 233-266.

Brown, Charles and James Medoff, "The Employer Size-Wage Effect," Journal of Political Economy, 1989, 97 (5), 1027-1059.

Campbell, David, Alan Carruth, Andrew Dickerson, and Francis Green, "Job insecurity and wages," The Economic Journal, 2007, 117 (518), 544-566.

Chamberlain, Gary, "Analysis of Covariance with Qualitative Data," Review of Economic Studies, 1980, 47, 225-238.

Cho, Seo-Young and Krishna Chaitanya Vadlamannati, "Compliance with the Anti-trafficking Protocol," European Journal of Political Economy, 2012, 28 (2), 249-265.

Chung, Ching-Fan and Arthur S. Goldberger, "Proportional Projections in Limited Dependent Variable Models," Econometrica, 1984, 52 (2), 531-534. 
Clark, Andrew, "What really matters in a job? Hedonic measurement using quit data," Labour economics, 2001, 8 (2), 223-242.

, "Unemployment as a Social Norm: Psychological Evidence from Panel Data," Journal of Labor Economics, 2003, 21, 323-351.

, Andreas Knabe, and Steffen Rätzel, "Boon or bane? Others' unemployment, well-being and job insecurity," Labour Economics, 2010, 17 (1), 52-61.

Cramer, J. S., "Robustness of Logit Analysis: Unobserved Heterogeneity and Misspecified Disturbances," Oxford Bulletin of Economics and Statistics, August 2007, 69 (4), 545-555.

Crinò, Rosario, "Offshoring, multinationals and labour market: a review of the empirical literature," Journal of Economic Surveys, 2009, 23 (2), 197-249.

Deaton, Angus and Margaret Irish, "Statistical models for zero expenditures in household budgets," Journal of Public Economics, 1984, 23 (1-2), 59-80.

Di Tella, Rafael, Robert J. MacCulloch, and Andrew J. Oswald, "Preferences over Inflation and Unemployment: Evidence from Surveys of Happiness," American Economic Review, 2001, 91, 335-341.

Dickerson, Andy and Francis Green, "Fears and realisations of employment insecurity," Labour Economics, 2012, 19 (2), 198-210.

Dreher, Axel and Noel Gaston, "Has Globalisation Really had no Effect on Unions?," Kyklos, 2007, 60 (2), 165-186.

Dumont, Michel, Glenn Rayp, and Peter Willemé, "Does internationalization affect union bargaining power? An empirical study for five EU countries," Oxford Economic Papers, 2006, 58 (1), 77-102.

, and _ _ "The bargaining position of low-skilled and high-skilled workers in a globalising world," Labour Economics, 2012, 19 (3), 312 - 319.

Ebenstein, Avraham, Ann E. Harrison, Margaret S. McMillan, and Shannon Phillips, "Estimating the Impact of Trade and Offshoring on American Workers Using the Current Population Surveys," Review of Economics and Statistics, forthcoming.

Eckel, Carsten and Hartmut Egger, "Wage bargaining and multinational firms," Journal of International Economics, 2009, 77 (2), 206-214.

Egger, Hartmut and Udo Kreickemeier, "Firm Heterogeneity And The Labor Market Effects Of Trade Liberalization," International Economic Review, 2009, 50 (1), 187-216.

Feenstra, Robert C. and Gordon H. Hanson, "Foreign Direct Investment, Outsourcing and Relative Wages," in Robert C. Feenstra, Gene M. Grossman, and D. A. Irwin, eds., The Political Economy of Trade Policy: Papers in Honor of Jagdish Bhagwati, Cambridge, Massechusetts: MIT Press, 1996, pp. 89-127.

and __ , "Globalization, Outsourcing, and Wage Inequality," American Economic Review, 1996, 86 (2), 240-245. 
and _ _ , "The Impact of Outsourcing and High-technology Capital on Wages: Estimates for the United States, 1979-1990," Quarterly Journal of Economics, 1999, 114 (3), 907-940.

Ferrer-i-Carbonell, Ada and Paul Frijters, "How Important is Methodology for the Estimates of the Determinants of Happiness?," Economic Journal, 2004, 114, 641-659.

Frey, Bruno and Alois Stutzer, "What Can Economists Learn from Happiness Research?," Journal of Economic Literature, 2002, 40 (2), 402-435.

Frijters, Paul and Tony Beatton, "The mystery of the U-shaped relationship between happiness and age," Journal of Economic Behavior $\&$ Organization, 2012, $82(23), 525-542$.

, Ingo Geishecker, John P. Haisken-De-New, and Michael A. Shields, "Can the Large Swings in Russian Life Satisfaction be Explained by Ups and Downs in Real Incomes?," Scandinavian Journal of Economics, 2006, 108 (3), $433-458$.

, John P. Haisken-DeNew, and Michael A. Shields, "Money Does Matter! Evidence From Increasing Real Income and Life Satisfaction in East Germany Following Reunification," American Economic Review, 2004, 94, 730-740.

Gaston, Noel, "The Effects of Globalisation on Unions and the Nature of Collective Bargaining," Journal of Economic Integration, 2002, 17, 377-396.

Geishecker, Ingo, "Simultaneity Bias in the Analysis of Perceived Job Insecurity and Subjective Well-Being," Economics Letters, 2012, 116 (3), 319-321.

and Holger Görg, "Winners and losers: A micro-level analysis of international outsourcing and wages," Canadian Journal of Economics, 2008, 41 (1), 243-270.

, __ , and Jakob Munch, "Do labour market institutions matter? Micro-level wage effects of international outsourcing in three European countries," Review of World Economics, 2010, 146, 179-198.

, Maximilian Riedl, and Paul Frijters, "Offshoring and job loss fears: An econometric analysis of individual perceptions," Labour Economics, 2012, 19 (5), $738-747$.

Goerke, Laszlo and Markus Pannenberg, "Risk Aversion, Collective Bargaining, and Wages in Germany," LABOUR, 2012, 26 (2), 156-173.

Green, Francis, Alan Felstead, and Brendan Burchell, "Job Insecurity and the Difficulty of Regaining Employment: An Empirical Study of Unemployment Expectations," Oxford Bulletin of Economics and Statistics, 2000, 62 (1), 855-883.

Greene, William H., "On the Asymptotic Bias of the Ordinary Least Squares Estimator of the Tobit Model," Econometrica, 1981, 49 (2), 505-513.

, "The behaviour of the maximum likelihood estimator of limited dependent variable models in the presence of fixed effects," Econometrics Journal, 2004, 7 (1), 98-119. 
Grossman, Gene M. and Esteban Rossi-Hansberg, "Trading Tasks: A Simple Theory of Offshoring," American Economic Review, 2008, 98 (5), 1978-1997.

Haisken-DeNew, John P. and Markus H. Hahn, "PanelWhiz: Efficient Data Extraction of Complex Panel Data Sets - An Example Using the German SOEP," Journal of Applied Social Science Studies, 2010, 130 (4), 643-654.

Harrison, Ann, John McLaren, and Margaret McMillan, "Recent Perspectives on Trade and Inequality," Annual Review of Economics, 2011, 3 (1), 261-289.

Helpman, Elhanan, "Trade, FDI, and the Organization of Firms," Journal of Economic Literature, 2006, 44 (3), 589-630.

Honoré, Bo E. and Ekaterini Kyriazidou, "Panel Data Discrete Choice Models with Lagged Dependent Variables," Econometrica, July 2000, 68 (4), 839-874.

Hummels, David, Rasmus Jørgensen, Jakob R. Munch, and Chong Xiang, "The Wage Effects of Offshoring: Evidence from Danish Matched Worker-Firm Data," NBER Working Papers 17496, National Bureau of Economic Research, Inc October 2011.

Kassenböhmer, Sonja C. and John P. Haisken-DeNew, "You're Fired! The Causal Negative Effect of Unemployment on Life Satisfaction," The Economic Journal, 2009, 119, 448-462.

Knabe, Andreas and Steffen Rätzel, "Scarring or Scaring? The Psychological Impact of Past Unemployment and Future Unemployment Risk," Economica, 2009, 119 (536), 448-462.

Kohler, Wilhelm, "International outsourcing and factor prices with multistage production," Economic Journal, 2004, 114 (494), C166-C185.

König, Jan and Erkki Koskela, "Does International Outsourcing Really Lower Workers Income?," Journal of Labor Research, 2011, 32 (1), 21-38.

Koskela, Erkki and Rune Stenbacka, "Equilibrium unemployment with outsourcing under labour market imperfections," Labour Economics, 2009, 16 (3), 284 290.

Layard, Richard, "Happiness and public policy: a challenge to the profession," The Economic Journal, 2006, 116 (510), C24-C33.

, Happiness: Lessons from a new science, Penguin, 2011.

Luechinger, Simon, "Valuing Air Quality Using The Life Satisfaction Approach," Economic Journal, 2009, 119, 482-515.

, Stephan Meier, and Alois Stutzer, "Why Does Unemployment Hurt the Employed? Evidence from the Life Satisfaction Gap Between the Public and the Private Sector," Journal of Human Resources, 2010, 45 (4), 998-1045.

Manski, Charles F., "Measuring Expectations," Econometrica, 2004, 72 (5), 13291376.

and John D. Straub, "Worker Perceptions of Job Insecurity in the Mid-1990s: Evidence from the Survey of Economic Expectations," The Journal of Human Resources, 2000, 35 (3), 447-479. 
Mincer, Jacob, Schooling, Experience, and Earnings, National Bureau of Economic Research, 1974.

Neve, Jan-Emmanuel De, Nicholas Christakis, James Fowler, and Bruno Frey, "Genes, economics, and happiness," Journal of Neuroscience, Psychology, and Economics, 2012, 5 (4), 193.

Nickell, Stephen, Patricia Jones, and Glenda Quintini, "A Picture of Job Insecurity Facing British Men," Economic Journal, 2002, 112 (476), 1-27.

Ranjan, Priya, "Offshoring, unemployment, and wages: The role of labor market institutions," Journal of International Economics, 2013, 89 (1), 172 - 186.

Ruud, Paul A., "Sufficient Conditions for the Consistency of Maximum Likelihood Estimation Despite Misspecification of Distribution in Multinomial Discrete Choice Models," Econometrica, January 1983, 51 (1), 225-228.

Scheve, Kenneth F. and Matthew J. Slaughter, "Economic Insecurity and the Globalization of Production," American Journal of Political Science, 2004, 48 (4), 662-674.

Schmidt, Christoph M. and Klaus F. Zimmermann, "Work Characteristics, Firm Size and Wages," The Review of Economics and Statistics, 1991, 73 (4), $705-710$.

Schmidt, Stefanie R., "Long-Run Trends in Workers' Beliefs about Their Own Job Security: Evidence from the General Social Survey," Journal of Labor Economics, 1999, 17 (4), 127-41.

Senik, Claudia, "When information dominates comparison: Learning from Russian subjective panel data.," Journal of Public Economics, 2004, 88, 9-10.

Sethupathy, Guru, "Offshoring, wages, and employment: Theory and evidence," European Economic Review, 2013, 62, 73-97.

Skaksen, Jan Rose, "International Outsourcing When Labour Markets Are Unionized," The Canadian Journal of Economics, 2004, 37 (1), 78-94.

Stephens, Jr., Melvin, "Job Loss Expectations, Realizations, and Household Consumption Behavior," Review of Economics and Statistics, 2004, 86 (1), 253-269.

Stevenson, Betsey and Justin Wolfers, "Economic Growth and Subjective WellBeing: Reassessing the Easterlin Paradox," Brookings Papers on Economic Activity, 2008, 2008 (1), 1-87.

van Praag, Bernard and Ada Ferrer-i-Carbonell, Happiness Quantified: A Satisfaction Calculus Approach, Oxford University Press, 2008.

Wagner, Gert G., Joachim R. Frick, and Jürgen Schupp, "The German SocioEconomic Panel Study (SOEP) - Scope, Evolution and Enhancements," Journal of Applied Social Science Studies, 2007, 127 (1), 139-169.

White, Halbert, "A Heteroskedasticity Consistent Covariance Matrix Estimator and a Direct Test for Heteroskedasticity," Econometrica, 1980, 48 (4), 817-838.

Winkelmann, Liliana and Rainer Winkelmann, "Why Are the Unemployed So Unhappy? Evidence from Panel Data.," Economica, 1998, 65, 1-15. 
Wooldridge, Jeffrey M., Econometric Analysis of Cross Section and Panel Data, 2nd ed., The MIT Press, 2010. 


\section{Eidesstattliche Erklärung}

Ich versichere an Eides Statt, dass ich die eingereichte Dissertation "Three Essays on Job Loss Fears and Offshoring" selbstständig verfasst habe. Anderer als der von mir angegebenen Hilfsmittel und Schriften habe ich mich nicht bedient. Alle wörtlich oder sinngemäß den Schriften anderer Autorinnen und/oder Autoren entnommenen Stellen habe ich kenntlich gemacht. 